\title{
Taxonomy on EEG Artifacts \\ Removal Methods, Issues, and Healthcare Applications
}

\author{
Vandana Roy, Hitkarini College of Engineering and Technology, India \\ Prashant Kumar Shukla, Jagran Lakecity University, India \\ Amit Kumar Gupta, KIET Group of Institutions, India \\ Vikas Goel, KIET Group of Institutions, India \\ Piyush Kumar Shukla, University Institute of Technology RGPV, India \\ Shailja Shukla, Jabalpur Engineering College, India
}

\begin{abstract}
Electroencephalogram (EEG) signals are progressively growing data widely known as biomedical big data, which is applied in biomedical and healthcare research. The measurement and processing of EEG signal result in the probability of signal contamination through artifacts which can obstruct the important features and information quality existing in the signal. To diagnose the human neurological diseases like epilepsy, tumors, and problems associated with trauma, these artifacts must be properly pruned assuring that there is no loss of the main attributes of EEG signals. In this paper, the latest and updated information in terms of important key features are arranged and tabulated extensively by considering the 60 published technical research papers based on EEG artifact removal method. Moreover, the paper is a review vision about the works in the area of EEG applied to healthcare and summarizes the challenges, research gaps, and opportunities to improve the EEG big data artifacts removal more precisely.
\end{abstract}

\section{KEYWORDS}

Artifact Removal, DWT, EEG, EEMD, EMG, EOG, ICA

\section{INTRODUCTION}

The Big Data biological processes have very complex procedures, which imply neural as well as hormonal stimuli and responses. These biomedical signals generally represent a collective electrical signal attained from any organ, signifying a physical variable of interest. To store and handle these Big Data different technologies are frequently applied in the biomedical and health-care field (Luo $\&$ Zhao, 2016) to facilitate health-care activities. The energy management for real-time Big Data is a critical issue. Thus, energy and performance trade-off in resource optimized model design for Big Data is discussed in (E. Baccarelli \& Stefa, 2016). 
The Biomedical Big Data cover a wide range of the following signal: electrooculogram (EOG), electroneurogram (ENG), electrogastrogram (EGG), phonocardiogram (PCG), carotid pulse (CP), vibromyogram(VMG), vibroarthogram(VAG), electrocardiogram (ECG), electroencephalogram (EEG), and electromyography (EMG). However, most widely used biomedical signals in healthcare applications are ECG, EEG, EMG, and EOG (Jiang \& Lin, 2007), (Mowla \& Paramesran, 2015).

The EEG signal is able to track changes within millisecond time-span, and is a good tool for analyzing brain activity (Urigüen \& Zapirain, 2015). Moreover, this EEG signal is preferred to other signals. Certain physiological signal such as SET tracks changes in the blood circulation and positron emission (PET) measures the change in metabolism which is indirect indicators of electrical activity belonging to the brain, while EEG specifically tests the electrical activity of the brain. This software will assist in pre-processing (Roy \& Shukla, 2019), (Bigdely \& Robbins, 2016) of the EEG data to enable data sharing, archiving, large-scale machine learning/data mining and (meta-) analysis.

Usually, EEG Signals can be classified based on their frequency, amplitude and shape. The most common classification is based on the frequency of EEG signals (i.e. alpha, beta, theta, and delta) (Chen \& Householder, 2018). Figure 1 shows the brain rhythms arranged according to increased frequencies. The brain waves with their frequency band and the corresponding brain activities are revealed in Table 1.

Table 1. Electroencephalography (EEG) Signal Frequency Bands.

\begin{tabular}{|l|l|l|}
\hline \multicolumn{1}{|c|}{ Name } & Frequency Band $(\mathbf{H z})$ & \multicolumn{1}{c|}{ Predominantly Brain Activity } \\
\hline Delta & 0.5 to 4 & Sleeping \\
\hline Theta & 4 to 8 & Dreaming, Meditation \\
\hline Alpha & 8 to 13 & Relaxation \\
\hline Beta & 13 to 36 & $\begin{array}{l}\text { Alert/Working } \\
\text { Problem Solving }\end{array}$ \\
\hline Gamma & 36 to 100 & Multisensory semantic matching Perceptual function \\
\hline
\end{tabular}

Figure 1. Fundamental EEG Bands classification. (http://www.yalescientific.org/2013/12/the-brink-of-death-a-new-perspective/)

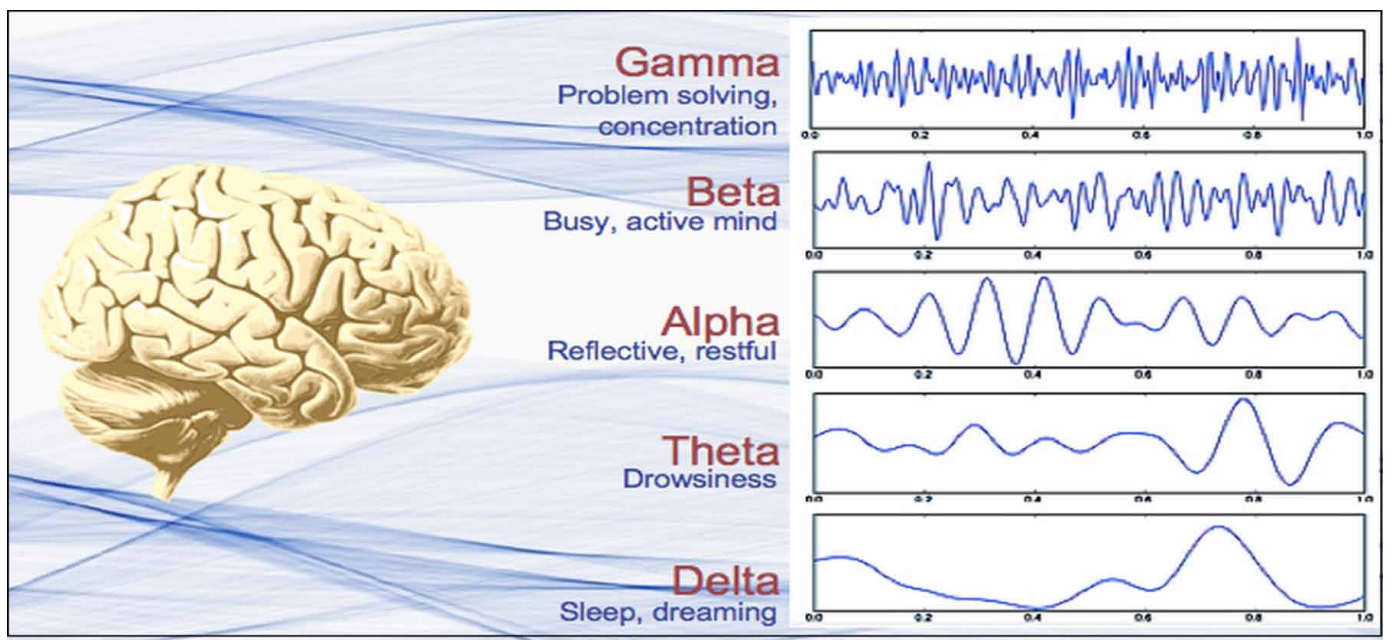




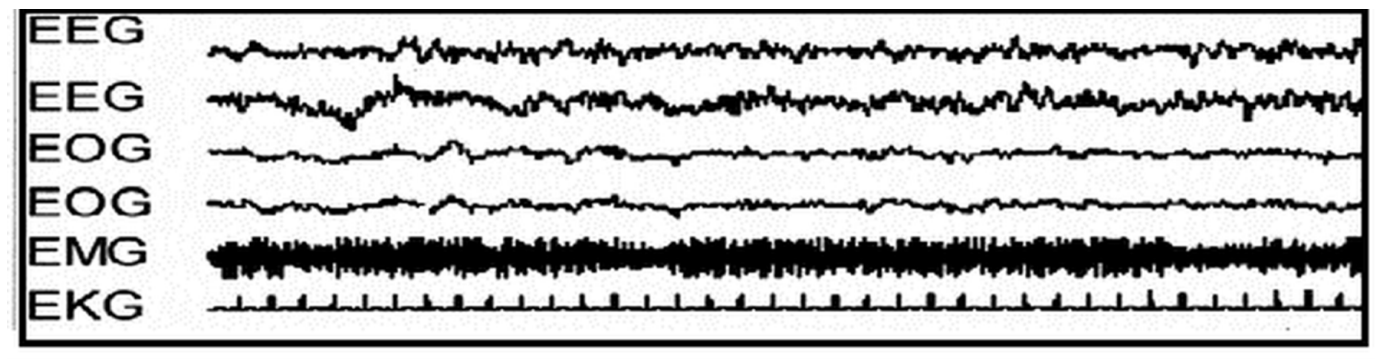

Furthermore, EEG signals are highly sensitive to movement of the subject and noises being introduced externally likewise human head activation, eye movements, musculature, nearby electrical device interference. The movement in human body changes electrode conductivity or physicochemical reactions occurred at the electrode sites results in the artifacts. These artifacts can be categorized as muscle artifacts (EMG), glossokinetic artifacts, eye blink artifacts (EOG), eye movement artifacts, ECG artifacts, pulse artifacts, respiration artifacts, skin artifacts etc.

Figure 2 shows some of the artifacts who have the major influence on the quality and information of the data and therefore, leading to an erroneous form of signals. Therefore, it is required to identify and prune the artifacts from the desired signal for better analysis and diagnosis of human neurological diseases. In this review paper, around 200 research papers based on artifact removal techniques have been studied and state of the art analysis of about 60 research papers details are presented in a comparative tabular form. This information is useful to conclude and summarize the challenges and gaps present in Big EEG Data artifact removal field and opportunities needed to improve the quandary area.

Usually, the EEG epochs having the signal amplitude larger than selected threshold value have been rejected. This approach is stubborn and no adaption is allowed hence results in loss of meaning full information. Moreover, these artifacts will get overlapped with original EEG signal. Therefore, the threshold-based rejections will loss the important information. Thus, an automated component-based approach for artifact separation is required to solve this problem. The approach must transform the linear decomposition of signals into different source components. The components after decomposition will provide the information according to the different source types. Consequently, artifacts information is collected from separate sources and the final signal is reconstructed without these artifact sources to get artifact removed signal (Sweeney \& Ward, 2013).

In general, the most frequently applied Big EEG Data artifact removal algorithms are:

- $\quad$ Blind Source Separations (ICA and CCA)

- EEMD

- Wavelet Transform (DWT and SWT)

The ephemeral information of these algorithms is discussed in next section.

The organization of this comprehensive review paper is as follows: section 2 overviews the existing artifact removal techniques employed for EEG artifact removal. In section 3, a comprehensive review of all the state-of-the-art EEG artifact removal-based research papers have been done. Various features from relevant artifact removal-based paper is compared in tabular form in section 4 and tables are attached as annexure. The summary prepared by the study of numerous research papers which are focused on specific artifact removal. Additionally, specific artifact removal methods are classified with our own experience in section 5. The conclusions are summed up with some recommendations in section 6. Some open issues related to artifact removal are also highlighted. 
Figure 3. Independent component analysis algorithm flow-chart

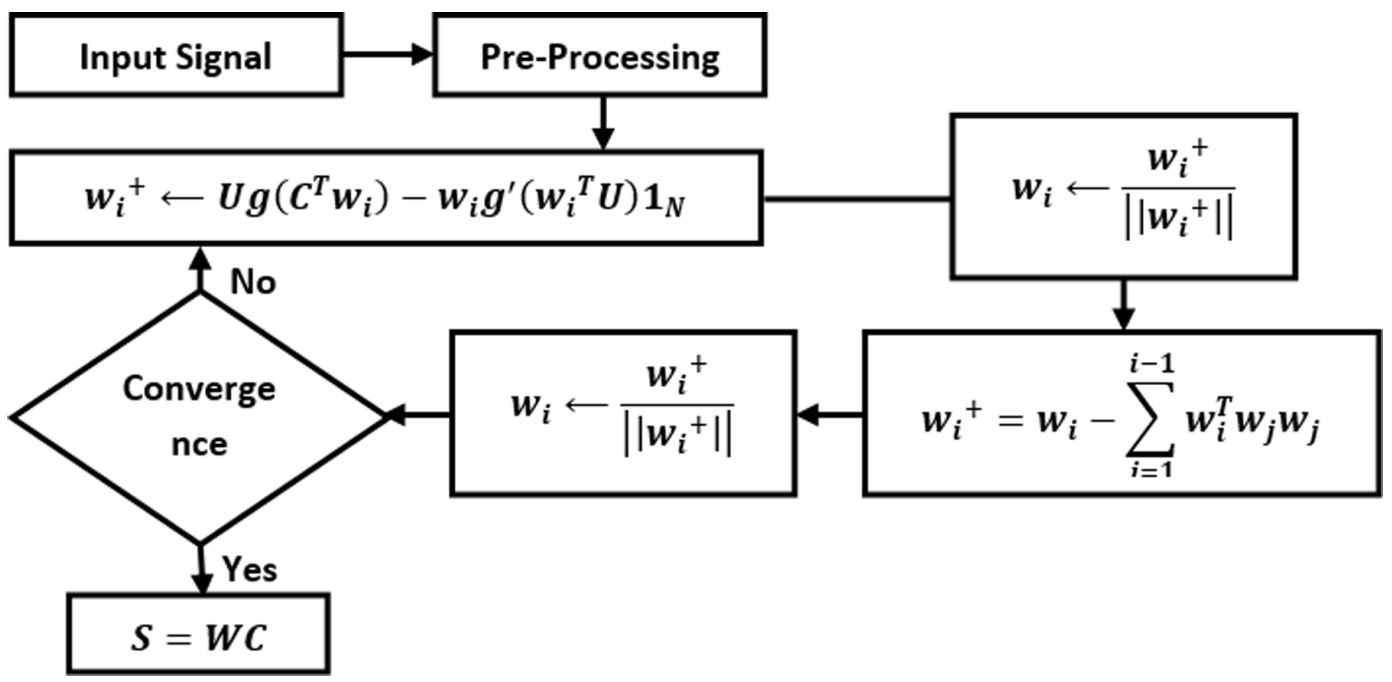

\section{BIG EEG DATA ARTIFACT REMOVAL TECHNIQUES}

\subsection{Blind Source Separation Algorithm}

The Blind source separation is based on an unsubstantiated learning algorithm for estimating and separating the sources and artifacts components. Most frequently, Blind Source Separation can be done through Independent component analysis (ICA) (Kanoga \& Mitsukura, 2015) and Canonical Correlation Analysis (CCA) (Soomro \& Yusoff, 2014).

\subsubsection{Independent Component Analysis (ICA)}

The EEG signal separation into independent components requires ICA algorithm which uses the statistical and computational techniques. The ICA algorithm considers mixture signal $C=\left[c_{1}, c_{2}, c_{j} \ldots c_{n}\right]$ as input and generated independent sources $S=\left[s_{1}, s_{2}, s_{j} \ldots s_{n}\right]$ where $\mathrm{W}$ is the $n \times m$ mixing matrix:

$$
S=W C
$$

Figure 3 shows the flow of ICA algorithm. Here, $w_{i}$ is column vector and $w_{i}^{+}$is temporary variable, $g($.$) and g^{\prime}($.$) represents first and the second derivate of nonlinear and non-quadratic$ functions. When the convergence is received $w_{i+1}$ must be made orthogonal with respect to Equation 1 in order to differentiate the new components. Nevertheless, ICA algorithm is centered on higher order statistics and we cannot determine the order and variance of independent component. Therefore, second order statistics-based algorithm CCA is preferred for EEG artifact removal discussed in the next section.

\subsubsection{Canonical Correlation Analysis (CCA)}

Canonical correlation analysis (CCA) is first proposed by Hotelling. CCA is an algorithm for determination of the linear association between two set variables. This is done by using the data variance and co-variance matrix (Soomro \& Yusoff, 2014).

The following are a number of linear combinations called A and B: 
$A_{P}=\left[a_{11}, a_{12}, \ldots . . a_{1 m}\right]^{T}$

$B_{Q}=\left[b_{11}, b_{12}, \ldots . . b_{1 n}\right]^{T}$

Let $\mathrm{C}_{\mathrm{pp}}$ and $\mathrm{C}_{\mathrm{qq}}$ be the variance of the $\mathrm{A}_{\mathrm{p}}$ and $\mathrm{B}_{\mathrm{Q}}$ respectively and $\mathrm{C}_{\mathrm{pq}}$ is the covariance between $\mathrm{A}_{\mathrm{P}}$ and $\mathrm{B}_{\mathrm{Q}}$. Then the above equation can be rewritten as:

$$
P^{*}=\frac{A_{p}^{T} C_{p p} B_{Q}}{\sqrt{ } A_{p}^{T} C_{p p} A_{p} \sqrt{ } B_{q}^{T} C_{q q} B_{q}}
$$

To achieve the best of self correlations, this $P^{*}$ should be maximum. Therefore, this optimization can be resolved by:

$$
C_{p p}^{-1} C_{p q} C_{q q}^{-1} C_{q p} A_{P}=\rho A_{P}
$$

$$
C_{q q}^{-1} C_{q p} C_{p p}^{-1} C_{p q} B_{Q}=\rho B_{Q}
$$

This $\rho$ signifies the Eigen value which is identical to square of $P^{*}$ :

$$
\rho=\sqrt{P^{*}}
$$

This canonical pair will be calculated and detached by calculating self-correlation and a mutual uncorrelation between sources input. Next subsection will discuss another effective EEG artifact removal algorithm namely Enhanced Empirical Mode Decomposition (EEMD).

\subsection{Enhanced Empirical Mode Decomposition (EEMD)}

Empirical mode decomposition algorithm is a non-linear way of representing a non-stationary signal into sum of zero-mean sections. This method disassembles a signal through an iterative method known as sifting in many intrinsic mode functions. The IMF1 function is the mean of the top and bottom enclosure of the original EEG signal, $x(t)$. Then the residual signal is obtained by subtracting IMF1 from $x(t)$. This cycle is iterated until the stop criterion is met (the remainder of the energy signal is near zero). The left residual signal is:

$$
P_{n}(t)=P_{n-1}(t)-I M F_{n}(t)
$$

where $P_{n}(t)=x(t)$.

Finally, the signal is reconstructed by adding all IMFs and residual signal as: 


$$
x(t)=P_{n}(t)+\sum_{i=1}^{N} I M F_{i}(t)
$$

The detection method of IMFs is sensitive to unwanted signal components in the surrounding. Such noises affect the process of EMD. Mode mixing therefore is used in order to eliminate the disparate amplitude oscillations of almost all IMF peaks, which can be randomly available in the entire dataset. Consequence, the EMD algorithm version as Ensemble Empirical Mode Decomposition (EEMD) was introduced as more powerful and noise-assisted (Chen \& Peng, 2014), which solves this mode of mixing dilemma and uses the average EMD ensembles which filter out IMFs for the signal provided. This method also depends on the noise level and amount of tests applied to the input signal. One another artifact removal approach is Wavelet Transform discussed briefly in the next section.

\section{WAVELET TRANSFORM}

The wavelet technique is used for more accurately filtering the corrupted signal. In the first stage, the mother wavelet should be selected and in the second step, the shape selection should be selected according to the source type. The signal is then subdivided into a variety of mother wavelet variants of time shifted and scaled version. Details and estimates were calculated at each level of the wavelet transformation. Then, artifact components are detected and removed by thresholds and finally other components are introduced to restore the refined signal without artifacts (Ghandeharion \& Erfanian, 2010).

The most widely used transforming wavelet is Discrete Wavelet Transform. However, neural signal information is important when removing EEG artifacts. Some recent work therefore shows that SWT is a great tool to extract signal artifacts that retain neural knowledge of the original signal (Chang \& Im, 2016).

Stationary Wavelet Transform (SWT), as no down sampling of the data is involved, is translation invariant (Ghandeharion \& Erfanian, 2010). The invariance of translation is achieved by removing down-and-up DWT samplers. In addition, the coefficients of the filter were up sampled $2^{(j-1)}$ at the $j^{\text {th }}$ level in the algorithm stage. In order to remove unpredictable motion artifact behavior from EEG signals, the SWT algorithm is preferred. The EEG signal is smooth over the duration as it includes all its important characteristics only.

These algorithms are frequently applied for available artifact suppression from EEG Big Data. Based on study and analysis of around 60 artifact removal research papers, the application frequency of artifact removal algorithms is summarized in Table 2. This extensive study is devoted to acquiring the best artifact removal algorithms for effective suppression of different artifacts from EEG signal.

Table 2 gives the recommendation that BSS-ICA algorithms are frequently applied artifacts suppression algorithm in single and two stages. However, this algorithm is based on higher order statistics and it results in complex and time-consuming approaches. Further, CCA algorithms are preferred over ICA due to simplicity (based on second order statistics). Moreover, EEMD algorithms are applied for single channel signal in order to convert single channel signal to multi-channel signals. The Wavelet Transform algorithms are also frequently applied both in single and two stages and some algorithm based on neural network and optimization algorithms are also applied for artifacts suppression. The state of art based on the type of artifact and applied artifacts removal algorithms is discussed in the next section. 
Table 2. Frequency of artifact removal algorithms on electroencephalography (EEG)

\begin{tabular}{|c|c|c|c|c|}
\hline Sr. No. & \multicolumn{2}{|c|}{ EEG Artifacts Removal Algorithms } & Number of Stages & Application \\
\hline \multirow[t]{4}{*}{1.} & \multirow{4}{*}{$\begin{array}{l}\text { Blind Source } \\
\text { Separation }\end{array}$} & \multirow{2}{*}{$\begin{array}{l}\text { Independent Component Analysis } \\
\text { (ICA) }\end{array}$} & Single Stage & 11 \\
\hline & & & Two-stage & 20 \\
\hline & & \multirow{2}{*}{$\begin{array}{l}\text { Canonical Correlation Analysis } \\
\text { (CCA) }\end{array}$} & Single Stage & 04 \\
\hline & & & Two-stage & 06 \\
\hline \multirow[t]{2}{*}{2.} & \multirow{2}{*}{\multicolumn{2}{|c|}{ Enhanced Empirical Mode Decomposition (EEMD) }} & Single Stage & 04 \\
\hline & & & Two-stage & 13 \\
\hline \multirow[t]{2}{*}{3.} & \multirow{2}{*}{\multicolumn{2}{|c|}{ Wavelet Transform (WT) }} & Single Stage & 11 \\
\hline & & & Two-stage & 15 \\
\hline 4. & \multicolumn{2}{|c|}{ Others (Neural Network based) } & Single and two stages & 04 \\
\hline
\end{tabular}

\section{LITERATURE SURVEY}

The most frequent EEG signal artifacts are EMG, EOG, and ECG. The state of the art is classified according to artifact types and their removal. The first review is emphasized on the research work done for removal of EOG and then focused on EMG artifact removal and as well as automatic detection and removal of artifacts have been reviewed and summarized.

Among all the artifacts EOG is the most dominant artifact. EOG artifacts are affecting the EEG signals at Frontal electrodes due to eye movements and eye blinks. These signals will spread throughout the scalp and contaminate the pure EEG signal. These artifacts are of high amplitude and low frequency in nature. As these EOG artifacts overlap spectrally to EEG signals, therefore it is very hard to eliminate by using conventional method (Jadhav \& Naik, 2014). ICA-LMS (Least Mean Square) algorithm have applied by (Mosquera \& Vázquez, 2010) and compared its performance with Recursive Least Squares (RLS) to eliminate EOG artifacts from EEG signal. In (Matiko \& Tudor, 2013) more effective ICA algorithm has been used to eliminate the EOG and wavelet-based amplitude modulation features and support vector machine classifier is implemented to extract the features of the EEG. This method is complex and has large computational time.

The computational time for EOG artifact removal has been minimized by using the Short Time Fourier Transform (STFT) in (Huang \& Fang, 2013) with less memory requirement. A wavelet transform-based adaptive filtering approach to eliminate rapid eye movement is proposed more accurately by (Betta \& Menicucci, 2013). Further, Soomro et al. (Soomro \& Jatoi, 2013), (Soomro \& Malik, 2013) and (Soomro \& Yusoff, 2014) have applied EEMD-CCA methodology to minimize the EOG artifact and compared their performance with EEMD-ICA approach of artifact removal and concluded that EEMD-CCA is more efficient with less computational time and much better signal artifact ratio (SAR) and correlation coefficient.

In (Bizopoulos \& Fotiadis, 2013) research has been improved with artifact detection and removal of EOG artifacts. In this work, detection is based on Normalized Correlation Coefficient (NCC) and EOG artifact removal is done by using EEMD approach, though detection is not so accurate. The sample entropy enhanced Wavelet-ICA have suggested by (Mahajan \& Morshed, 2013) for removal of EOG artifact and compared the performance with Zeroing-ICA and Wavelet ICA and proved better. Further, performance is improved by using improved multi-scale sample entropy and kurtosis with wavelet transform to recognize and eradicate the independent blink component (Mahajan \& Morshed, 2015). To remove Ocular Artifacts more effectively in (Ge \& Hong, 2014) the Fourth Order Tensor 
Method (FOOBI) is applied and compared the performance with ICA and showed that FOOBI is better than ICA.

An automatic detection and suppression of ocular artifact is suggested by (Majmudar \& Morshed, 2015) with DWT algorithm and compared its performance with SWT. The result shows that DWT processing time is 25 times faster than SWT for EOG artifact elimination. However, neural information is not preserved so well. Therefore, a real-time approach based on artificial intelligence (AI) to remove EOG artifacts has been employed by using Wavelet Neural Network algorithm (WNN). In the WNN algorithm, EOG behaviors have been learned first and then after training artifacts are removed accordingly. This approach is more computationally efficient in real-time application than ICA (Nguyen \& Li, 2015). An improved approach with a combination of ICA and WNN is proposed by (Burger \& Heever, 2015) to remove EOG from EEG signal. These detection algorithms are complex and have more computation time. A wavelet-based approach is proposed in (Zhao \& Qiu, 2015) to remove EOG with CCA as well and proved better performance compared with ICA, CCA, and WICA.

To reduce the complexity of the medical systems for healthcare, the single channel systems are preferred over multichannel systems. Therefore, Single channel EEG ocular artifact removal has been suggested by (Patel \& Mariyappa, 2015) with EEMD-PCA approach and recommended this method for large input EEG data. The faster artifact removal algorithm termed as Complete EEMD (CEEMD) and ICA been proposed by (Kanoga \& Mitsukura, 2015) to eliminate eye blink artifact from single channel EEG. Auxiliary, performance is compared and showed better than WICA, EMDICA and EEMDICA. Further, EOG artifact removal method based on Wavelet Transform (DWT and SWT) with the universal and statistical threshold have proposed by (Khatun \& Morshed, 2015) and concluded that SWT with statistical threshold shows better performance than DWT for preserving the neural information of EEG while DWT with statistical threshold has fast execution time in comparison to another method.

Further, some research works have focused on adaptive artifact removal for EOG and EMG both, as in (Mowla \& Paramesran, 2015). The artifacts are identified foremost with the classification and then EOG artifacts have been removed by Second Order Blind Identification (SOBI)-SWT and EMG artifacts filtered with CCA-SWT. This adaptive algorithm presented improved results in comparison to existing methods of artifact removal.

Recently EMG artifact removal has been focused by some researchers. The artifacts potential were generated due to the movement or contraction of muscles, swallow, walks and talks. The EMG artifacts are of wide spectral distribution than the signal generated in the human brain. Moreover, this EMG can be easily removed on the basis of duration and frequency. The performance of EMD, CCA, ICA and WT for EMG artifact removal have compared (Safieddine \& Merlet, 2012) and concluded that for low SNR, EMD-ICA combination algorithm is effective and for high SNR, 2T-EMD or Contrast Maximisation 2 (CoM2) works better than other methods. Correspondingly DWT or CCA is preferred if numerical complexity is taken into account.

In addition, for EMG artifact removal (Teng \& Wang, 2014) the multivariate-EMD method was compared to the ICA based approach by using SNR and MSE as parameter. However, (Chen \& Ward, 2014) proposed EEMD-CCA and EEMD-IVA (Single Channel EEG data deletion EMG) and concluded that EEMD-CCA is outperformed by IVA. In addition, the EEMD-MCCA method is extended and the best results are shown (Chen \& Peng, 2014). The EMG artifacts have suppressed in (Anastasiadou \& Mitsis, 2014), (Anastasiadou \& Mitsis, 2015) by CCA and CCA-WT methodology to remove EMG and applied, analyzed practically for patients with epilepsy. All the EEG artifacts removal-based research papers are compared in tabular form by considering some important key features and attached as the annexure. 


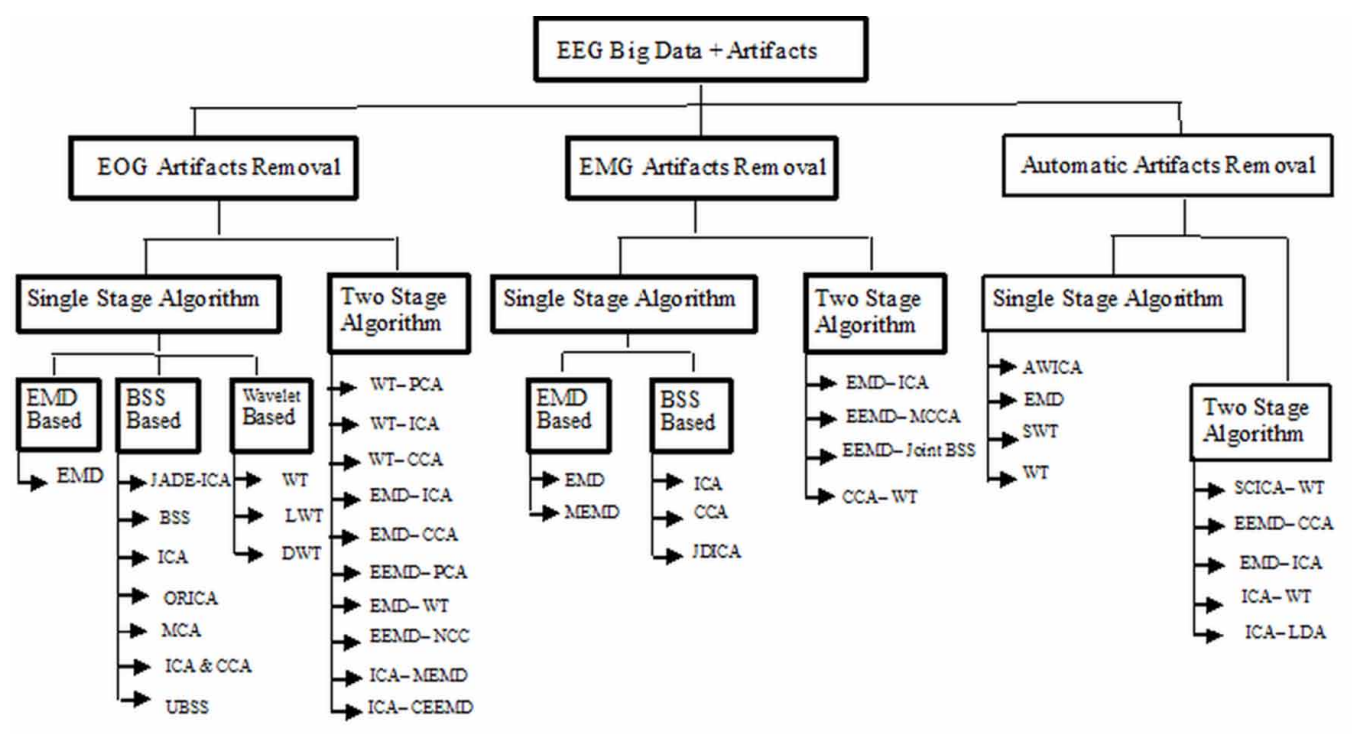

\section{ASSESSMENT TABLE}

The numerous state-of-the-art research papers based on EEG artifact removal have been studied and summarized based on some features and tabulated as in Annexure section. The EEG Signal artifacts removal algorithm effectiveness are characterized by some evaluation metrics such as Efficiency, Feasibility, Complexity, Speed, Correlation Coefficient, Peak to Signal Noise Ratio (PSNR), Root Mean Square Error (RMSE), etc. All these evaluation metrics are compared and tabulated according to the research work done for specific artifact removal. Initially classification is focused on the progress of research work done for EOG artifact removal as tabulated in Annexure A and further classified for adaptive artifact removal as in Annexure B. The progress of the work for EMG artifact removal is presented in Annexure C. Annexure D contains the algorithms and their effectiveness evaluation for automatic artifact detection and removal. The study and analysis of these tabular comparisons suggest valuable conclusion which is discussed in subsequent section.

\section{SUMMARY}

In the healthcare system as the ambulatory device applications have increased, the EEG-based applications have been also increased accordingly. In real time applications, some unintended signals (i.e. artifacts) need to remove so as to improve the analysis and diagnosis of human neurological diseases for healthcare. Most undesired Big EEG Data artifact elements are EMG, EOG, ECG and motion artifacts. The taxonomy of artifacts removal algorithms according to artifacts are shown in Figure 4.

Figure 4 summarizes the various state of the art algorithms applied exclusively to remove the artifacts in the EEG signal. The algorithms are classified according to the artifacts types. It has been also analyzed from the above figure that two-stage algorithms are more effective to remove the artifacts than single stage algorithms. Moreover, the type of signal input is also an important aspect of analysis. If the signal is multichannel signal then ICA or Wavelet Transform based algorithms are applied to suppress the artifacts, however, if EEG signal is single channel then EMD based approaches 
Table 3. Artifact removal algorithms applied according to the artifact type

\begin{tabular}{|l|l|}
\hline \multicolumn{1}{|c|}{ Type of Artifact } & \multicolumn{1}{c|}{ Artifact Removal Algorithms } \\
\hline $\begin{array}{l}\text { Electrooculogram } \\
\text { (EOG) }\end{array}$ & $\begin{array}{l}\text { 1. BSS (PCA, ICA, CCA) is frequently applied as single stage approach } \\
\text { 2. WT-BSS is applicable for multichannel input two-stage approaches } \\
\text { 3. EEMD-BSS is applicable for single channel input two-stage approaches } \\
\text { 4. Two-stage approaches present most effective EOG artifact suppression }\end{array}$ \\
\hline & $\begin{array}{l}\text { 1. EEMD and BSS are applied for Single stage approaches } \\
\text { 2. EEMD-BSS are applied for single channel two-stage approach }\end{array}$ \\
Electromyogram & $\begin{array}{l}\text { 3. CCA-WT is applied for multi-channel two-stage approach } \\
\text { 4. After BSS approaches SWT algorithm application presents most effective EMG artifact }\end{array}$ \\
\hline $\begin{array}{l}\text { Automatic Artifact } \\
\text { setection and }\end{array}$ & $\begin{array}{l}\text { 1. EMD, ICA, SWT algorithms are applied as single stage approaches } \\
\text { Removal }\end{array}$ \\
\hline
\end{tabular}

are applied initially to convert single channel signal to multichannel and then BSS or WT based approaches have been applied to eliminate the artifacts more effectively.

The major cause of EMG artifacts is due to frontalis and temporal muscles. In the classical work (Mijovic \& Huffel, 2010) EEMD-ICA method have applied to remove the muscle artifact; however, this muscle artifact removal process was improved by (Chen \& Ward, 2014) through EEMD-CCA algorithm. This EEMD-CCA algorithm is compared and proved better than the performance of EEMD-ICA. Further, in (Chen \& Peng, 2014) EEMD-MCCA is applied to improve the EMG artifact removal by increasing PSNR and reducing the RMSE values in comparison to the existing muscle artifact removal methodologies available. The algorithm CCA-WT has implemented by (Anastasiadou \& Mitsis, 2015) to attain best correlation coefficients for removal of EMG artifacts.

The most corrupting artifact in EEG signal is Electrooculogram (EOG), generated due to eyelid movement and eye blinking. The Haar wavelet-based ICA method is applied in (Mahajan \& Morshed, 2013) to suppress EOG artifacts and used entropy as a statistical measure. Further, in (Mahajan \& Morshed, 2015) an automatic EOG artifact detection with WICA has been employed and statistical measure is considered as modified multi-scale entropy. To compare the performance the ROC curve is plotted which shows significant improvement in sensitivity and specificity. The complexity and computational time of artifact removal algorithm are reduced by CCA method in (Soomro \& Yusoff, 2014) and compared with an existing ICA method to remove EOG artifacts. Further, (Mowla \& Paramesran, 2015) have implemented SOBI-SWT to improve the EOG artifact removal performance.

The automatic detection and correction of artifact algorithm have been employed by (Chuang \& Lin, 2014) with the independent component ensemble to remove eye blink, EOG, EMG adaptively. Further, (Radüntz \& Meffert, 2015) have used ICA-LDA algorithm as an automatic, reliable, realtime capable and practical tool for automatic detection and correction of artifacts from EEG signal.

Above study and investigation summarize that the particular artifact removal algorithms are effective according to the type of input artifacts whose information is recapitulated in Table 3.

Table 3 suggests that BSS algorithms are most effective for EOG artifact removal; CCA-WT is most effective for EMG artifact suppression.

PSNR, RMSE, Correlation coefficient, and complexity are the key factors for any artifact removal methods. This artifact removal can be done by using some efficient techniques as CCA, ICA, DWT, SWT, EEMD etc. These methodologies are faster, reliable and accurate for separation of different artifacts (EOG, EMG, ECG etc.) from the input EEG signal. These artifact removal methods can be applied to either single channel or multiple channel input EEG signal. This input EEG signal can be of different recording duration and also can be of different sampling rate and data. Some artifact 


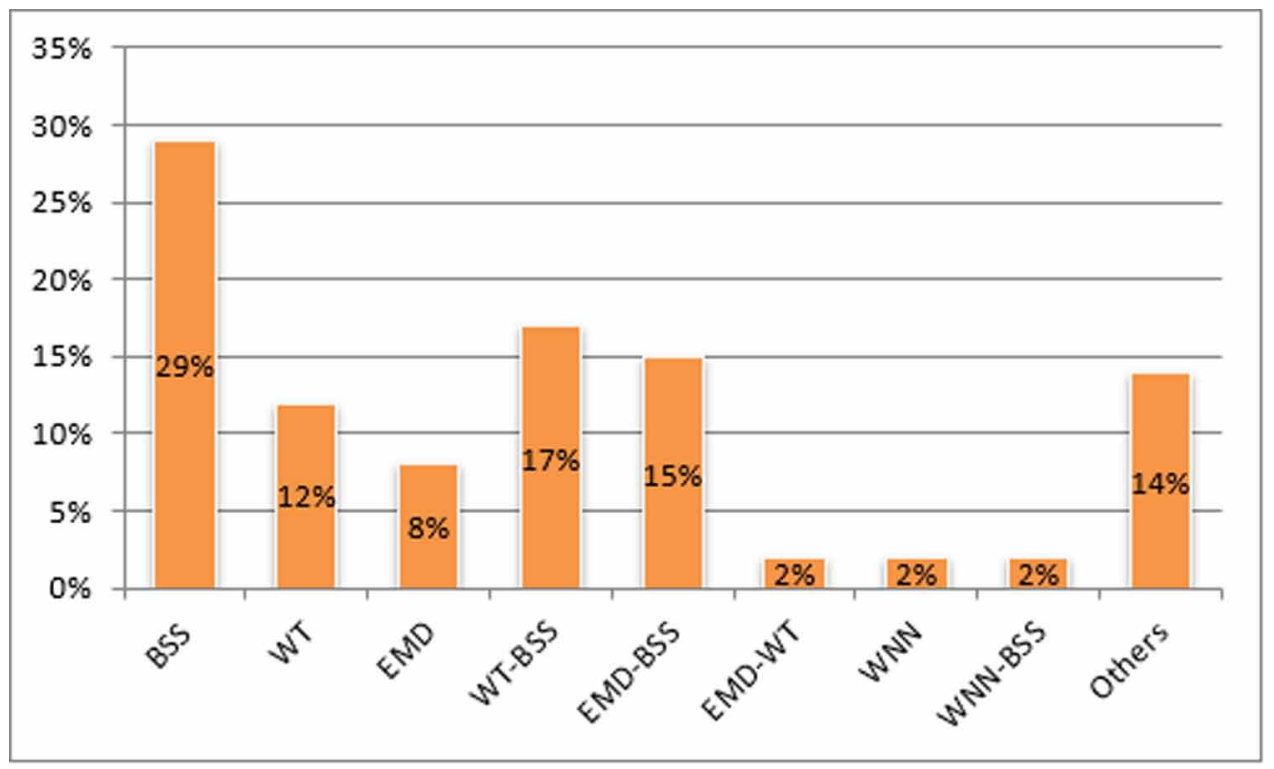

removal methods are feasible with some applied conditions as SNR values, a number of channels, type of diseases, etc.

Commencing the study of the published technical and review articles of EEG artifact removal, it can be summarized that the high PSNR value resemblance to the better EEG signal quality and least RMSE value indicates improved artifact separation. The improved correlation coefficient (Teng \& Wang, 2014) indicates that improved identification and separation of artifacts from the input noisy EEG signal can be attained those results in better source separation. The complexity and quality of artifact removal techniques can be affected by the speed and accuracy factors of the algorithm. The complexity of the methodology is varied according to the employed artifact removal methods and their computational time. The computational time of ICA is much higher than CCA, EEMD, DWT algorithms for artifact removal. Furthermore, minimum computational time is taken by DWT (Safieddine \& Merlet, 2012). The computational time and complexity will affect the execution speed of artifact removal methods. Therefore, the improved computational time will diminish the execution speed of the algorithm. Thus, these all key features will suggest the adaptability of artifact removal algorithms according to the input and types of artifact. Moreover, Figure 5 shows a graphical representation of percentage artifact removal methodologies employed in literature for EEG signal only.

The review and summary of the research papers state that almost $29 \%$ research papers used BSS algorithm as effective artifact removal technique, among them $47 \%$ focused on removal of EOG, 18\% applied the BSS algorithm to remove EMG, 6\% deals with ECG and 12\% automated the algorithm for artifact removal. Further, 12\% used WT algorithm, 8\% applied EMD algorithm, $15 \%$ applied cascading of EMD and BSS algorithm, 17\% WT and BSS algorithm combination, 2\% used the combination of EMD and WT approach, and remaining 4\% algorithm used an automated approach for artifact removal.

The various artifact removal methodologies as discussed above are of mere importance and very helpful in healthcare for diagnosis of neurological disease such as epilepsy, tumour, sleep apnea, etc. Research is still going on for the improvement of artifact removal of EEG which will definitely lead to the better diagnosis and treatment of neurological disorders. 


\section{CONCLUSION}

On the basis of the extensive study of the above-mentioned research papers, it is concluded that the artifact removal methods are an imperative pre-processing step for Big EEG Data signals. This cleaned EEG signal will support more accurate diagnosis and analysis of neurological diseases in the medical field. In literature, research work is basically focused on removal of EOG, EMG and motion artifact. The comprehensive review work is categorized according to the removal methodologies employed for various artifacts in the EEG signals.

Most frequently applied artifact removal algorithms in literature are EEMD, DWT, SWT, ICA, CCA and sometimes combinations of these methodologies. These methods have been compared based on some performance evaluation parameters as PSNR, RMSE, and correlation coefficient, etc. and proved the effective results using simulations. Finally, according to study and analysis of these research papers, it can be concluded that Blind Source Separation techniques are the most widely employed algorithms to remove the EOG artifacts from EEG signals. As these BSS algorithms are based on source separation and once artifact source is identified then their removal will be easier. Moreover, EMG artifacts available in EEG signal are better suppressed by wavelet transform. These Wavelet Transform algorithms will smooth out the EMG artifacts broad spectrum randomness available in the EEG signal while preserving the neural information. The Review analysis of abovementioned research papers concludes that cascading of different artifact removal algorithms can be more optimal for eliminating various artifacts from EEG signal. Therefore, processing of the signal will improve the quality of the signal, which will be helpful in analysis and diagnosis of neurological diseases in health care. 


\section{REFERENCES}

Akhtar, M. T., \& James, C. J. (2012). Employing Spatially Constrained ICA and Wavelet Denoising, for Automatic Removal of Artifacts from Multichannel EEG Data. Signal Processing, 92(2), 401-416. doi:10.1016/j. sigpro.2011.08.005

Anastasiadou, M., Christodoulakis, M., Papathanasiou, E. S., Papacostas, G. D., \& Mitsis, G. D. (2015, August). Automatic Detection and Removal of Muscle Artifacts from Scalp EEG Recordings in Patients with Epilepsy. In Proceedings of the 37th Annual International Conference of the IEEE Engineering in Medicine and Biology Society (EMBC) (pp. 1946-1950). IEEE. doi:10.1109/EMBC.2015.7318765

Anastasiadou, M., Hadjipapas, A., Christodoulakis, M., Papathanasiou, E. S., \& Mitsis, G. D. (2014, November). Detection and Removal of Muscle Artifacts from Scalp EEG Recordings in Patients with Epilepsy. In Proceedings of the 2014 IEEE International Conference on Bioinformatics and Bioengineering (pp. 291-296). IEEE. doi:10.1109/BIBE.2014.52

Babu, P. A., \& Prasad, K. V. S. V. R. (2011, June). Removal of Ocular Artifacts from EEG Signals using Adaptive Threshold PCA and Wavelet Transforms. In Proceedings of the 2011 International Conference on Communication Systems and Network Technologies (pp. 572-575). IEEE. doi:10.1109/CSNT.2011.122

Baccarelli, E., Cordeschi, N., Mei, A., Panella, M., Shojafar, M., \& Stefa, J. (2016). Energy-Efficient Dynamic Traffic Offloading and Reconfiguration of Networked Data Centers for Big Data Stream Mobile Computing: Review, Challenges, and a Case Study. IEEE Network, 30(2), 54-61. doi:10.1109/MNET.2016.7437025

Betta, M., Gemignani, A., Landi, A., Laurino, M., Piaggi, P., \& Menicucci, D. (2013, July). Detection and Removal of Ocular Artifacts from EEG Signals for an Automated REM Sleep Analysis. In Proceedings of the 2013 35th Annual International Conference of the IEEE Engineering in Medicine and Biology Society (EMBC) (pp. 5079-5082). IEEE. doi:10.1109/EMBC.2013.6610690

Bigdely-Shamlo, N., Makeig, S., \& Robbins, K. A. (2016). Preparing Laboratory and Real-World EEG Data for Large-Scale Analysis: A Containerized Approach. Frontiers in Neuroinformatics, 10(7). PMID:27014048

Bizopoulos, P. A., Al-Ani, T., Tsalikakis, D. G., Tzallas, A. T., Koutsouris, D. D., \& Fotiadis, D. I. (2013, July). An Automatic Electroencephalography Blinking Artefact Detection and Removal Method based on Template Matching and Ensemble Empirical Mode Decomposition. In Proceedings of the 2013 35th Annual International Conference of the IEEE Engineering in Medicine and Biology Society (EMBC) (pp. 5853-5856). IEEE. doi:10.1109/EMBC.2013.6610883

Burger, C., \& Heever, D. (2015). Removal of EOG Artefacts by Combining Wavelet Neural Network and Independent Component Analysis. Biomedical Signal Processing and Control, 15, 67-79. doi:10.1016/j. bspc.2014.09.009

Chang, W. D., \& Im, C. (2016). Detection of Eye Blink Artifacts from Single Prefrontal Channel Electroencephalogram. Computer Methods and Programs in Biomedicine, 124, 19-30. doi:10.1016/j. cmpb.2015.10.011 PMID:26560852

Chen, X., He, C., \& Peng, H. (2014). Removal of Muscle Artifacts from Single-Channel EEG based on Ensemble Empirical Mode Decomposition and Multi-Set Canonical Correlation Analysis. Journal of Applied Mathematics, $2014,1-11$.

Chen, X., Liu, A., Peng, H., \& Ward, R. (2014). A Preliminary Study of Muscular Artifact Cancellation in Single-Channel EEG. Sensors (Basel), 14(10), 18370-18389. doi:10.3390/s141018370 PMID:25275348

Chuang, C. H., Ko, L. W., Lin, Y. P., Jung, T. P., \& Lin, C. T. (2013). Independent Component Ensemble of EEG for Brain-Computer Interface. IEEE Transactions on Neural Systems and Rehabilitation Engineering, 22(2), 230-238. doi:10.1109/TNSRE.2013.2293139 PMID:24608683

Daly, I., Scherer, R., Billinger, M., \& Müller-Putz, G. (2015). Force: Fully Online and Automated Artifact Removal for Brain-Computer Interfacing. IEEE Transactions on Neural Systems and Rehabilitation Engineering, 23(5), 725-736. doi:10.1109/TNSRE.2014.2346621 PMID:25134085

Ge, S., Han, M., \& Hong, X. (2014). A Fully Automatic Ocular Artifact Removal from EEG Based on FourthOrder Tensor Method. Biomedical Engineering Letters, 4(1), 55-63. doi:10.1007/s13534-014-0118-2 
Ghandeharion, H., \& Erfanian, A. (2006, August). A Fully Automatic Method for Ocular Artifact Suppression from EEG Data using Wavelet Transform and Independent Component Analysis. In Proceedings of the 2006 International Conference of the IEEE Engineering in Medicine and Biology Society (pp. 5265-5268). IEEE. doi:10.1109/IEMBS.2006.259609

Ghandeharion, H., \& Erfanian, A. (2010). A Fully Automatic Ocular Artifact Suppression from EEG Data using Higher Order Statistics: Improved Performance by Wavelet Analysis. Medical Engineering \& Physics, 32(7), 720-729. doi:10.1016/j.medengphy.2010.04.010 PMID:20466582

Grouiller, F., Vercueil, L., Krainik, A., Segebarth, C., Kahane, P., \& David, O. (2007). A Comparative Study of Different Artefact Removal Algorithms for EEG Signals Acquired During Functional MRI. NeuroImage, 38(1), 124-137. doi:10.1016/j.neuroimage.2007.07.025 PMID:17766149

Hsu, W. Y., Lin, C. H., Hsu, H. J., Chen, P. H., \& Chen, I. R. (2012). Wavelet-Based Envelope Features with Automatic EOG Artifact Removal: Application to Single-Trial EEG Data. Expert Systems with Applications, 39(3), 2743-2749. doi:10.1016/j.eswa.2011.08.132

Hu, J., Wang, C. S., Wu, M., Du, Y. X., He, Y., \& She, J. (2015). Removal of EOG and EMG Artifacts from EEG using Combination of Functional Link Neural Network and Adaptive Neural Fuzzy Inference System. Neurocomputing, 151, 278-287. doi:10.1016/j.neucom.2014.09.040

Huang, K. J., Liao, J. C., Shih, W. Y., Feng, C. W., Chang, J. C., Chou, C. C., \& Fang, W. C (2013, October). A Real-Time Processing Flow for ICA Based EEG Acquisition System with Eye Blink Artifact Elimination. In SiPS 2013 Proceedings (pp. 237-240). IEEE.

Islam, M. K., Rastegarnia, A., Nguyen, A. T., \& Yang, Z. (2014). Artifact Characterization and Removal in Vivo Neural Recording. Journal of Neuroscience Methods, 226, 110-123. doi:10.1016/j.jneumeth.2014.01.027 PMID:24512692

Islam, M. K., Rastegarnia, A., \& Yang, Z. (2015). A Wavelet-Based Artifact Reduction from Scalp EEG for Epileptic Seizure Detection. IEEE Journal of Biomedical and Health Informatics, 20(5), 1321-1332. doi:10.1109/ JBHI.2015.2457093 PMID:26186797

Jadhav, P. N., Shanamugan, D., Chourasia, A., Ghole, A. R., Acharyya, A. A., \& Naik, G. (2014, August). Automated Detection and Correction of Eye Blink and Muscular Artefacts in EEG Signal for Analysis of Autism Spectrum Disorder. In Proceedings of the 2014 36th Annual International Conference of the IEEE Engineering in Medicine and Biology Society (pp. 1881-1884). IEEE. doi:10.1109/EMBC.2014.6943977

Jiang, J. A., Chao, C. F., Chiu, M. J., Lee, R. G., Tseng, C. L., \& Lin, R. (2007). An Automatic Analysis Method for Detecting and Eliminating ECG Artifacts in EEG. Computers in Biology and Medicine, 37(11), 1660-1671. doi:10.1016/j.compbiomed.2007.03.007 PMID:17517386

Kanoga, S., \& Mitsukura, Y. (2015). Eye Blink Artifact Rejection in Single-Channel Electroencephalographic Signals by Complete Ensemble Empirical Mode Decomposition and Independent Component Analysis. Engineering in Medicine and Biology Society, 121-124.

Khatun, S. M., \& Morshed, B. I. (2015). Comparative Analysis of Wavelet Based Approaches for Reliable Removal of Ocular Artifacts from Single Channel EEG. Electro/Information Technology (EIT), 335-340.

Kiamini, M. A., \& Ahmadi, M. (2009). Elimination of Ocular Artifacts from EEG Signals using the Wavelet Transform and Empirical Mode Decomposition. Electrical Engineering/Electronics, Computer, Telecommunications and Information Technology, 1-4.

Korhonen, R. J., \& Sarvas, J. (2011). Removal of Large Muscle Artifacts from Transcranial Magnetic StimulationEvoked EEG by Independent Component Analysis. Medical \& Biological Engineering \& Computing, 49(4), 397-407. doi:10.1007/s11517-011-0748-9 PMID:21331656

Kumar, P. A., \& Vimal, C. (2009). An Adaptive Method to Remove Ocular Artifacts from EEG Signals using Wavelet Transform. Journal of Applied Sciences Research, 5(7), 741-745.

Luo, J., \& Zhao, Y. (2016). Big Data Application in Biomedical Research and Healthcare: A Literature Review. Biomedical Informatics Insights, 8, 1-10. doi:10.4137/BII.S31559 PMID:26843812 
Lyzhko, E. H., \& Siniatchkin, M. (2015). Comparison of Three ICA Algorithms for Ocular Artifact Removal from TMS-EEG Recordings. Engineering in Medicine and Biology Society, 1926-1929.

Mahadevan, A. A., \& Mugler, D. (2008). Ballistocardiogram Artifact Removal in EEG-FMRI Signals using Discrete Hermite Transforms. Signal Processing, 2(2), 839-853.

Mahajan, R., \& Morshed, B. I. (2013). Sample Entropy Enhanced Wavelet-ICA Denoising Technique for Eye Blink Artifact Removal from Scalp EEG Dataset. Neural Engineering (NER), 1394-1397.

Mahajan, R., \& Morshed, B. I. (2015). Unsupervised Eye Blink Artifact Denoising of EEG Data with Modified Multi-Scale Sample Entropy, Kurtosis, and wavelet-ICA. IEEE Journal of Biomedical and Health Informatics, 19(1), 158-165. doi:10.1109/JBHI.2014.2333010 PMID:24968340

Majmudar, C. A., \& Morshed, B. I. (2015). Real-Time Hybrid Ocular Artifact Detection and Removal for Single Channel EEG. Electro/Information Technology (EIT), 330-334.

Mammone, N. F., \& Morabito, F. C. (2012). Automatic Artifact Rejection from Multichannel Scalp EEG by Wavelet ICA. Sensors (Basel), 12(3), 533-541. doi:10.1109/JSEN.2011.2115236

Matiko, J. B., \& Tudor, J. (2013). Real Time Eye Blink Noise Removal from EEG Signals using Morphological Component Analysis. Engineering in Medicine and Biology Society (EMBC), 13-16.

Mert, A., \& Akan, A. (2013). Hilbert-Huang Transform based Hierarchical Clustering for EEG Denoising. Signal Processing Conference (EUSIPCO), 1-5.

Mijovic, B., \& Huffel, S. V. (2010). Source Separation from Single-Channel Recordings by Combining EmpiricalMode Decomposition and Independent Component Analysis. IEEE Transactions on Biomedical Engineering, 57(9), 2188-2196. doi:10.1109/TBME.2010.2051440 PMID:20542760

Mosquera, C. G., \& Vázquez, A. N. (2010). Automatic Removal of Ocular Artefacts using Adaptive Filtering and Independent Component Analysis for Electroencephalogram Data. Signal Process IET, 6(2), 99-106. doi:10.1049/iet-spr.2010.0135

Mourad, N., \& Niazy, R. K. (2013). Automatic Correction of Eye Blink Artifact in Single Channel Recording using EMD and OMP. Signal Processing Conference (EUSIPCO), 1-5.

Mowla, M. R., \& Paramesran, R. (2015). Artifacts-Matched Blind Source Separation and Wavelet Transform for Multichannel EEG Denoising. Biomedical Signal Processing and Control, 22, 111-118. doi:10.1016/j. bspc.2015.06.009

Nguyen, H. A., \& Li, J. (2015). EOG Artifact Removal using a Wavelet Neural Network. Neurocomputing, 97, 374-389. doi:10.1016/j.neucom.2012.04.016

Patel, R., Sengottuvel, S., Janawadkar, M. P., Gireesan, K., Radhakrishnan, T. S., \& Mariyappa, N. (2016). Ocular Artifact Suppression Ffrom EEG using Ensemble Empirical Mode Decomposition with Principal Component Analysis. Computers \& Electrical Engineering, 54, 78-86. doi:10.1016/j.compeleceng.2015.08.019

Priyadharsini, S. S., \& Rajan, S. E. (2014). An Efficient Method for the Removal of ECG Artefact from Measured EEG Signal using PSO Algorithm. Int J Advance Soft ComputAppl, 6(1), 1-19.

Radüntz, T., \& Meffert, B. (2015). EEG Artifact Elimination by Extraction of ICA-Component Features using Image Processing Algorithms. Journal of Neuroscience Methods, 243, 84-93. doi:10.1016/j.jneumeth.2015.01.030 PMID:25666892

Romero, S., \& Barbanoj, M. J. (2008). A Comparative Study of Automatic Techniques for Ocular Artifact Reduction in Spontaneous EEG Signals Based on Clinical Target Variables: A Simulation Case. Computers in Biology and Medicine, 38(3), 348-360. doi:10.1016/j.compbiomed.2007.12.001 PMID:18222418

Romo-Vazquez, R., Ranta, R., Louis-Dorr, V., \& Maquin, D. (2007). EEG Ocular Artefacts and Noise Removal. Annual International Conference of the IEEE Engineering in Medicine and Biology - Proceedings, 5445-5448.

Safieddine, D. K., \& Merlet, I. (2012). Removal of Muscle Artifact from EEG Data: Comparison between Stochastic (ICA AND CCA) and Deterministic (EMD and Wavelet) based Approaches. EURASIP Journal on Advances in Signal Processing, 12, 1-15. 
Salwani, M. D., \& Jasmy, Y. (2005). Comparison of Few Wavelets to Filter Ocular Artifacts in EEG Using Lifting Wavelet Transform. TENCON, 1-6.

Sardouie, S. H., \& Merlet, I. (2015). An Efficient Jacobi-Like Deflationary ICA Algorithm: Application to EEG Denoising. IEEE Signal Processing Letters, 22(8), 1198-1202. doi:10.1109/LSP.2014.2385868

Soomro, M. H., \& Jatoi, M. A. (2013). Automatic Eye-Blink Artifact Removal Method based on EMD-CCA. Complex Medical Engineering (CME), 186-190.

Soomro, M. H., \& Malik, A. S. (2013). A Method for Automatic Removal of Eye Blink Artifacts from EEG Based on EMD-ICA. Signal Processing and its Applications (CSPA), 129-134.

Soomro, M. H., \& Yusoff, M. (2014). Comparison of Blind Source Separation Methods for Removal of Eye Blink Artifacts from EEG. Intelligent and Advanced Systems (ICIAS), 1-6.

Sweeney, K. T., \& Onaral, B. (2012). A Methodology for Validating Artifact Removal Techniques for Physiological Signals. Information Technology in Biomedicine, 16(5), 918-926. doi:10.1109/TITB.2012.2207400 PMID:22801522

Sweeney, K. T., \& Ward, T. E. (2013). The Use Of Ensemble Empirical Mode Decomposition with Canonical Correlation Analysis as a Novel Artifact Removal Technique. IEEE Transactions on Biomedical Engineering, 60(1), 97-105. doi:10.1109/TBME.2012.2225427 PMID:23086501

Teng, C. Z., \& Wang, G. (2014). The Removal of EMG Artifact from EEG Signals by the Multivariate Empirical Mode Decomposition. Signal Processing, Communications and Computing, 873-876.

Turnip, A. (2014). JADE-ICA Algorithm for EOG Artifact Removal in EEG Recording. Technology, Informatics, Management, Engineering, and Environment, 270-274.

Urigüen, J. A., \& Zapirain, B. (2015). EEG Artifact Removal-State-of-the-Art and Guidelines. Journal of Neural Engineering, 12(3), 031001-031043. doi:10.1088/1741-2560/12/3/031001 PMID:25834104

Vigon, L. S., \& Fernandes, R. (2000). Quantitative Evaluation of Techniques for Ocular Artefact Filtering of EEG Waveforms. Science Measurement and Technology, 147(5), 219-228. doi:10.1049/ip-smt:20000475

Wang, G. T., \& Yan, X. (2015). The Removal of EOG Artifacts from EEG Signals using Independent Component Analysis and Multivariate Empirical Mode Decomposition. Biomedical and Health Informatics, 991-997.

Zhao, C., \& Qiu, T. (2015). An Automatic Ocular Artifacts Removal Method Based on Wavelet-Enhanced Canonical Correlation Analysis. Engineering in Medicine and Biology Society (EMBC), 4191-4194.

Zhao, Q., \& Peng, H. (2014). Automatic Identification and Removal of Ocular Artifacts in EEG-Improved Adaptive Predictor Filtering for Portable Applications. IEEE Transactions on Nanobioscience, 13(2), $109-117$. doi:10.1109/TNB.2014.2316811 PMID:24802943 


\section{APPENDIX A}

Table 4. Feature comparison table for EOG artifact removal

\begin{tabular}{|c|c|c|c|c|c|c|}
\hline \multirow[b]{2}{*}{$\begin{array}{l}\text { Sequence } \\
\text { Number }\end{array}$} & \multicolumn{6}{|c|}{ Authors Name and feature comparison of their paper } \\
\hline & 1 & 2 & 3 & 4 & 5 & 6 \\
\hline $\begin{array}{l}\text { Authors } \\
\backslash \\
\text { Features }\end{array}$ & $\begin{array}{l}\text { (Vigon \& } \\
\text { Fernandes, } \\
2000)\end{array}$ & $\begin{array}{l}\text { (Salwani } \\
\text { \& Jasmy, } \\
\text { 2005) }\end{array}$ & $\begin{array}{l}\text { (Ghandeharion\& } \\
\text { Erfanian, 2006) }\end{array}$ & $\begin{array}{l}\text { (Vazquez \& } \\
\text { Maquin, 2007) }\end{array}$ & $\begin{array}{l}\text { (Romero \& } \\
\text { Barbanoj, } \\
\text { 2008) }\end{array}$ & $\begin{array}{l}\text { (Kiamini } \\
\text { \& Ahmadi, } \\
\text { 2009) }\end{array}$ \\
\hline $\begin{array}{l}\text { Used } \\
\text { techniques }\end{array}$ & JADE-ICA & lwt & wT-ica & wd-ica & BSS & EMD-WT \\
\hline $\begin{array}{l}\text { Artifact } \\
\text { removed }\end{array}$ & EOG & EOG & EOG & EOG & EOG & EOG \\
\hline Year & 2000 & 2005 & 2006 & 2007 & 2008 & 2009 \\
\hline $\operatorname{PSNR}(\mathrm{dB})$ & $>50$ & High & Satisfactory & 20 & 40 & 20 \\
\hline $\operatorname{RMSE}(\mu \mathrm{V})$ & Low & Low & 0.3 & $\begin{array}{l}0.0453^{\mathrm{a}} \\
0.3040^{\mathrm{b}}\end{array}$ & 1.35 & $2.20 \mathrm{E}-01$ \\
\hline Feasible & $\begin{array}{l}\text { If SNR above } \\
50\end{array}$ & $\begin{array}{l}\text { with Haar } \\
\text { computation }\end{array}$ & $\begin{array}{l}\text { With } \\
\text { Thresholding }\end{array}$ & Yes & $\begin{array}{l}\text { Good with } \\
\text { AMUSE and } \\
\text { SOBI }\end{array}$ & Yes \\
\hline $\begin{array}{l}\text { Efficiency/ } \\
\text { Reliable }\end{array}$ & Yes & High & $96.4 \%$ & $\begin{array}{l}\text { Efficient } \\
\text { with SURE } \\
\text { algorithm }\end{array}$ & Reliable & $\begin{array}{l}\text { Highly } \\
\text { Efficient }\end{array}$ \\
\hline Complexity & Medium & Least & Complex & Complex & Medium & Less \\
\hline Speed & Low & Very high & Low & Low & Medium & High \\
\hline Data Duration & $10 \mathrm{~s}$ & $10 \mathrm{~s}$ & $4 \mathrm{~s}$ & $8 \mathrm{~s}$ & $3 \mathrm{~min}$ & $2 \mathrm{~s}$ \\
\hline $\begin{array}{l}\text { Sampling rate } \\
(\mathrm{Hz})\end{array}$ & 125 & 256 & 256 & 256 & 100 & 250 \\
\hline Sample data & 1250 & 2560 & - & - & - & 500 \\
\hline Channel & 32 & $\begin{array}{l}10-20 \\
\text { system }\end{array}$ & $10-20$ system & 4 & 10-20 system & 64 \\
\hline $\begin{array}{l}\text { Average } \\
\text { Correlation } \\
\text { coefficient }\end{array}$ & $\begin{array}{l}0.99(\mathrm{JADE}), \\
0.98(\mathrm{ICA})\end{array}$ & Satisfactory & $0.1579^{\mathrm{a}}, 0.1776^{\mathrm{b}}$ & $.7698^{\mathrm{a}}, .7076^{\mathrm{b}}$ & Good & High \\
\hline
\end{tabular}

LWT- Lifting Wavelet Transform

Number of channels- ${ }^{*}$, First Subject - $a$, Second Subject - $b$ 


\section{APPENDIX B}

Table 5. Feature comparison table for EOG artifact removal continued

\begin{tabular}{|c|c|c|c|c|c|c|}
\hline \multirow[b]{2}{*}{$\begin{array}{l}\text { Sequence } \\
\text { Number }\end{array}$} & \multicolumn{6}{|c|}{ Authors Name and feature comparison of their paper } \\
\hline & 7 & 8 & 9 & 10 & 11 & 12 \\
\hline $\begin{array}{l}\text { Authors } \\
\backslash \\
\text { Features }\end{array}$ & $\begin{array}{l}\text { (Kumar \& } \\
\text { Vimal, 2009) }\end{array}$ & $\begin{array}{l}\text { (Mosquera } \\
\text { \&Vázquez, } \\
\text { 2010) }\end{array}$ & $\begin{array}{l}\text { (Ghandeharion\& } \\
\text { Erfanian, 2010) }\end{array}$ & $\begin{array}{l}\text { (Babu \& } \\
\text { Prasad, } \\
\text { 2011) }\end{array}$ & $\begin{array}{l}\text { (Zhao \& Qiu, } \\
\text { 2015) }\end{array}$ & $\begin{array}{l}\text { (Nguyen \& Li, } \\
2015 \text { ) }\end{array}$ \\
\hline Used techniques & wt & ica & ICA-WT & PCA-WT & CCA-WT & WNN \\
\hline Artifact removed & EOG & EOG & EOG & EOG & EOG & EOG \\
\hline Year & 2009 & 2010 & 2010 & 2011 & 2015 & 2015 \\
\hline PSNR (dB) & Good & 0.8 & High & 19.1103 & 14.5699 & - \\
\hline $\operatorname{RMSE}(\mu \mathrm{V})$ & Low & 0.35 & 0.025 & 7.45E-09 & Low & 19.2154 \\
\hline Feasible & Yes & Fair & Yes & Low & $\begin{array}{l}\text { Needs Little } \\
\text { signal alteration }\end{array}$ & Yes \\
\hline $\begin{array}{l}\text { Efficiency/ } \\
\text { Reliable }\end{array}$ & $\begin{array}{l}\text { Improved } \\
\text { Quality }\end{array}$ & $\begin{array}{l}\text { Effective } \\
\text { Denoising }\end{array}$ & $97.8 \%$ & $\begin{array}{l}\text { Comparable } \\
\text { high }\end{array}$ & $\begin{array}{l}\text { Better than ICA } \\
\text { CCA and wICA }\end{array}$ & $\begin{array}{l}\text { Accurate } \\
\text { than Wavelet } \\
\text { Thresholding }\end{array}$ \\
\hline Complexity & Least & Complex & Complex & Medium & Moderate & Medium \\
\hline Speed & High & Low & High & Medium & Medium & Low \\
\hline Data Duration & $10 \mathrm{~s}$ & $10 \mathrm{~s}$ & $60 \mathrm{~s}$ & $400 \mathrm{~ms}$ & $4 \mathrm{~s}$ & $30 \mathrm{~s}$ \\
\hline $\begin{array}{l}\text { Sampling rate } \\
(\mathrm{Hz})\end{array}$ & 128 & 200 & 256 & 128 & 250 & 128 \\
\hline Sample data & - & 2000 & - & 15000 & 1000 & 3840 \\
\hline Channel & 4 & $10-20$ system & $10-20$ system & 2 & 32 & 32 \\
\hline $\begin{array}{l}\text { Average } \\
\text { Correlation } \\
\text { coefficient }\end{array}$ & 0.68 & 0.9945 & Medium & - & 0.97 & 0.9 \\
\hline
\end{tabular}

WNN- Wavelet Neural Network 


\section{APPENDIX C}

Table 6. Feature comparison table for EOG artifact removal continued

\begin{tabular}{|c|c|c|c|c|c|c|}
\hline \multirow[b]{2}{*}{ Sequence Number } & \multicolumn{6}{|c|}{ Authors Name and feature comparison of their paper } \\
\hline & 13 & 14 & 15 & 16 & 17 & 18 \\
\hline $\begin{array}{l}\text { Authors } \\
\text { I } \\
\text { Features }\end{array}$ & $\begin{array}{l}\text { (Hsu \& } \\
\text { Chen, 2012) }\end{array}$ & $\begin{array}{l}\text { (Soomro \& Malik, } \\
\text { 2013) }\end{array}$ & $\begin{array}{l}\text { (Soomro \& } \\
\text { Jatoi, 2013) }\end{array}$ & $\begin{array}{l}\text { (Huang \& } \\
\text { Fang, 2013) }\end{array}$ & $\begin{array}{l}\text { (Bizopoulos\& } \\
\text { Fotiadis, 2013) }\end{array}$ & $\begin{array}{l}\text { (Matiko \& } \\
\text { Tudor, 2013) }\end{array}$ \\
\hline Used techniques & ica-dwt & Emd-cca & emd-ica & ORICA & NCC-EEMD & MCA \\
\hline Artifact removed & eog & EOG & EOG & EOG & Eog & EOG \\
\hline Year & 2012 & 2013 & 2013 & 2013 & 2013 & 2013 \\
\hline $\operatorname{PSNR}(\mathrm{dB})$ & Good & $6.0^{\mathrm{a} / 2.2^{\mathrm{b}}}$ & 1.04761 & Good & 7.649 & $\begin{array}{l}\text { Sufficient } \\
\text { High }\end{array}$ \\
\hline $\operatorname{RMSE}(\mu \mathrm{V})$ & Low & Min & Low & Low & 0.215 & Low \\
\hline Feasible & Yes & $\begin{array}{l}\text { Suitable for Online } \\
\text { Removal }\end{array}$ & Not Feasible & Yes & Satisfactory & Yes \\
\hline Efficiency/ Reliable & $84.4 \%$ & $\begin{array}{l}\text { Efficient if electrode } \\
\text { placed distant }\end{array}$ & $\begin{array}{l}\text { Effective } \\
\text { Denoising }\end{array}$ & Satisfactory & Satisfactory & Reliable \\
\hline Complexity & Complex & Medium & $\begin{array}{l}\text { Highly } \\
\text { Complex }\end{array}$ & Complex & Less & Less \\
\hline Speed & Low & Medium & Least & Least & High & High \\
\hline Data Duration & $20 \mathrm{~s}$ & $500 \mathrm{~ms}$ & $800 \mathrm{~ms}$ & $25 \mathrm{~s}$ & $4 \mathrm{~s}$ & $4 \mathrm{~s}$ \\
\hline Sampling rate $(\mathrm{Hz})$ & 256 & 250 & 250 & 128 & 1000 & 256 \\
\hline Sample data & - & 1000 & 200 & - & 250 & 1024 \\
\hline Channel & 5 & 2 & 2 & 7 & $10-20$ system & 1 \\
\hline $\begin{array}{l}\text { Average Correlation } \\
\text { coefficient }\end{array}$ & High & $0.908808^{\mathrm{a}} / 0.864514^{\mathrm{b}}$ & 0.871094 & 0.9135 & 0.767 & 0.94 \\
\hline
\end{tabular}

ORICA- Online Recursive ICA, NCC- Normalized Cross Correlation, MCA- Minor Component Analysis

Number of channels- ${ }^{*}$, First Subject - $a$, Second Subject -b 


\section{APPENDIX D}

Table 7. Feature comparison table for EOG artifact removal continued

\begin{tabular}{|c|c|c|c|c|c|c|}
\hline \multirow[b]{2}{*}{$\begin{array}{l}\text { Sequence } \\
\text { Number }\end{array}$} & \multicolumn{6}{|c|}{ Authors Name and feature comparison of their paper } \\
\hline & 19 & 20 & 21 & 22 & 23 & 24 \\
\hline $\begin{array}{l}\text { Authors } \\
\backslash \\
\text { Features }\end{array}$ & $\begin{array}{l}\text { (Mourad \& } \\
\text { Niazy, 2013) }\end{array}$ & $\begin{array}{l}\text { Mahajan } \\
\text { \& Morshed, } \\
\text { 2013) }\end{array}$ & $\begin{array}{l}\text { (Betta \& } \\
\text { Menicucci, } \\
\text { 2013) }\end{array}$ & $\begin{array}{l}\text { Mahajan } \\
\text { \& Morshed, } \\
\text { 2015) }\end{array}$ & $\begin{array}{l}\text { (Zhao \& } \\
\text { Peng, 2014) }\end{array}$ & $\begin{array}{l}\text { (Turnip, } \\
\text { 2014) }\end{array}$ \\
\hline Used techniques & EMD & WT-ICA & WT & ICA-DWT & DWT-APF & JADE-ica \\
\hline Artifact removed & EOG & EOG & EOG & EOG & EOG & Eog \\
\hline Year & 2013 & 2013 & 2013 & 2014 & 2014 & 2014 \\
\hline $\operatorname{PSNR}(\mathrm{dB})$ & High & Satisfactory & High & High & Low & $3.590^{\mathrm{a}}, 5.393^{\mathrm{b}}$ \\
\hline $\operatorname{RMSE}(\mu \mathrm{V})$ & Medium & Low & 0.0002 & 0.89 & 0.6443 & Low \\
\hline Feasible & Yes & Fair & Yes & $\begin{array}{l}\text { Low no. of } \\
\text { channels }\end{array}$ & Yes & Yes \\
\hline $\begin{array}{l}\text { Efficiency/ } \\
\text { Reliable }\end{array}$ & $\begin{array}{l}\text { Effective } \\
\text { for Single } \\
\text { Channel }\end{array}$ & $94 \%$ & $\begin{array}{l}\text { Effective and } \\
\text { Reliable }\end{array}$ & $\begin{array}{l}\text { Effective } \\
\text { Denoising }\end{array}$ & $\begin{array}{l}\text { Fast } \\
\text { prediction } \\
\text { speed, low } \\
\text { nMSE }\end{array}$ & Effective \\
\hline Complexity & Less & Complex & Least & Complex & Medium & Complex \\
\hline Speed & High & Low & Very high & Low & Medium & Low \\
\hline Data Duration & $20 \mathrm{~s}$ & $30 \mathrm{~s}$ & $25 \mathrm{~s}$ & $78 \mathrm{~s}$ & $80 \mathrm{~s}$ & $80 \mathrm{~s}$ \\
\hline $\begin{array}{l}\text { Sampling rate } \\
(\mathrm{Hz})\end{array}$ & 250 & 128 & 500 & 128 & 256 & 128 \\
\hline Sample data & 4100 & - & - & 5120 & 5120 & - \\
\hline Channel & $\begin{array}{l}10-20 \\
\text { electrode } \\
\text { System }\end{array}$ & 14 & $10-20$ system & $10-20$ system & $10-20$ system & 6 \\
\hline $\begin{array}{l}\text { Average } \\
\text { Correlation } \\
\text { coefficient }\end{array}$ & 0.79 & 0.6704 & Good & 0.7771 & High & Good \\
\hline
\end{tabular}

APF- Adaptive Predictor Filter

First Subject - a, Second Subject -b 


\section{APPENDIX E}

\section{Table 8. Feature Comparison Table for EOG Artifact Removal Continued}

\begin{tabular}{|c|c|c|c|c|c|c|}
\hline \multicolumn{7}{|c|}{ Authors Name and feature comparison of their paper } \\
\hline $\begin{array}{l}\text { Sequence } \\
\text { Number }\end{array}$ & 25 & 26 & 27 & 28 & 29 & 30 \\
\hline $\begin{array}{l}\text { Authors } \\
1 \\
\text { Features }\end{array}$ & $\begin{array}{l}\text { (Soomro\& } \\
\text { Yusoff, 2014) }\end{array}$ & $\begin{array}{l}\text { (Ge \& Hong, } \\
\text { 2014) }\end{array}$ & $\begin{array}{l}\text { (Wang \& Yan, } \\
\text { 2015) }\end{array}$ & $\begin{array}{l}\text { (Majmudar \& } \\
\text { Morshed, 2015) }\end{array}$ & $\begin{array}{l}\text { (Lyzhko \& } \\
\text { Siniatchkin, 2015) }\end{array}$ & $\begin{array}{l}\text { (Kanoga \& } \\
\text { Mitsukura, 2015) }\end{array}$ \\
\hline Used techniques & cca \& Ica & UBSS & MEMD-ICA & DWT & ica & ceemd-ica \\
\hline Artifact removed & EOG & EOG & EOG & EOG & eog & eog \\
\hline Year & 2014 & 2014 & 2015 & 2015 & 2015 & 2015 \\
\hline $\operatorname{PSNR}(\mathrm{dB})$ & $\begin{array}{l}7.6891^{\mathrm{a}}, 6.5274^{\mathrm{b}}, \\
-3.5709^{\mathrm{c}}\end{array}$ & Good & High & Good & High & $11.86 \pm 3.60$ \\
\hline $\operatorname{RMSE}(\mu \mathrm{V})$ & Low & Low & 22 & Low & 0.1569 & Low \\
\hline Feasible & High & Yes & Yes & Yes & Fair & Yes \\
\hline $\begin{array}{l}\text { Efficiency/ } \\
\text { Reliability }\end{array}$ & $\begin{array}{l}\text { Reliable } \\
\text { algorithm }\end{array}$ & Effective & Efficient & Effective & Good & $11.86 \pm 3.60 \%$ \\
\hline Complexity & High complex & Less & Complex & Least & Complex & High \\
\hline Speed & Least & High & Low & Very High & Low & Least \\
\hline Data Duration & $10 \mathrm{~s}$ & $10 \mathrm{~s}$ & $3-8 \mathrm{~s}$ & $35 \mathrm{~s}$ & $100 \mathrm{~ms}$ & $60 \mathrm{~s}$ \\
\hline Sampling rate $(\mathrm{Hz})$ & 256 & 256 & 500 & 256 & 5000 & 256 \\
\hline Sample data & 2560 & 2560 & - & 128 & - & - \\
\hline Channel number & 18 & 16 & $10-20$ system & 1 & 64 & 15 \\
\hline $\begin{array}{l}\text { Average } \\
\text { correlation } \\
\text { coefficient }\end{array}$ & $\begin{array}{l}.5739^{\mathrm{a}}, .8229^{\mathrm{b}}, \\
.8427^{\mathrm{c}}\end{array}$ & $0.9963 \pm 0.0060$ & $\begin{array}{l}(.789 / .165)^{\mathrm{a}}, \\
(.747 / .186)^{\mathrm{b}}, \\
(.795 / .15)^{\mathrm{c}}\end{array}$ & $\begin{array}{l}\left(.304^{*} / .303^{\wedge}\right) \\
\mathrm{a},\left(.297^{*} / .299^{\wedge}\right)^{\mathrm{b}}, \\
\left(.506^{*} / .603^{\wedge}\right)^{\mathrm{c}}\end{array}$ & 0.91 & High \\
\hline
\end{tabular}

UBSS- Undetermined Blind Source Separation, MEMD- Multivariate EMD, CEEMD- Complete EEMD

First Subject- a, Second Subject- b, Third Subject-c 


\section{APPENDIX F}

Table 9. Feature Comparison Table for EOG artifact removal continued

\begin{tabular}{|c|c|c|c|c|}
\hline \multicolumn{5}{|c|}{ Authors Name and feature comparison of their paper } \\
\hline Sequence Number & 31 & 32 & 33 & 34 \\
\hline $\begin{array}{l}\text { Authors } \\
\backslash \\
\text { Features }\end{array}$ & $\begin{array}{l}\text { (Patel \& Mariyappa, } \\
\text { 2015) }\end{array}$ & $\begin{array}{l}\text { (Chang \& Im, } \\
\text { 2016) }\end{array}$ & $\begin{array}{l}\text { (Burger \& Heever, } \\
\text { 2015) }\end{array}$ & $\begin{array}{l}\text { (Khatun \& Morshed, } \\
\text { 2015) }\end{array}$ \\
\hline Used techniques & EEMD-PCA & MSDW & Wnn-ica & WT \\
\hline Artifact removed & EOG & EOG & eog & eog \\
\hline Year & 2015 & 2015 & 2015 & 2015 \\
\hline $\mathrm{PSNR}(\mathrm{dB})$ & -18 & Good & Good & - \\
\hline $\operatorname{RMSE}(\mu \mathrm{V})$ & $0.31 \pm 0.12$ & $0.1536 \pm .1321$ & 5.3731 & Min with Swt-st \\
\hline Feasible & With EOG only & Yes & Yes & $\begin{array}{l}\text { Good for single } \\
\text { channel }\end{array}$ \\
\hline Efficiency/ Reliability & $92 \%$ & Good & $\begin{array}{l}\text { Efficient with } \\
\text { minimum loss }\end{array}$ & Efficient with dwt-st \\
\hline Complexity & Moderate & Low & Highly complex & Least \\
\hline Speed & Medium & High & Least & Least \\
\hline Data Duration & $25 \mathrm{~s}$ & $15 \mathrm{~s}$ & $10 \mathrm{~s}$ & $105 \mathrm{~s}$ \\
\hline Sampling rate $(\mathrm{Hz})$ & 1000 & 2048 & 1000 & 128 \\
\hline Sample data & 5000 & - & - & 5000 \\
\hline Channel number & 64 & 1 & 128 & 14 \\
\hline $\begin{array}{l}\text { Average correlation } \\
\text { coefficient }\end{array}$ & Satisfactory & $0.1893 \pm 0.735$ & $0.99,0.92$ & $0.41 \pm 0.21$ \\
\hline
\end{tabular}

MSDW- Maximum Sliding Window 


\section{APPENDIX G}

Table 10. Feature Comparison Table for EOG, EMG and ECG Artifact Removal

\begin{tabular}{|c|c|c|c|c|c|c|}
\hline \multicolumn{7}{|c|}{ Authors Name and feature comparison of their paper } \\
\hline $\begin{array}{l}\text { Sequence } \\
\text { Number }\end{array}$ & 1 & 2 & 3 & 4 & 5 & 6 \\
\hline $\begin{array}{l}\text { Authors } \\
\backslash \\
\text { Features }\end{array}$ & $\begin{array}{l}\text { (Jadhav \& } \\
\text { Naik, 2014) }\end{array}$ & $\begin{array}{l}\text { (Hu \& She, } \\
\text { 2015) }\end{array}$ & $\begin{array}{l}\text { (Mowla \& } \\
\text { Paramesran, } \\
2015 \text { ) }\end{array}$ & $\begin{array}{l}\text { (Jiang \& } \\
\text { Lin, 2007) }\end{array}$ & $\begin{array}{l}\text { (Grouiller\& } \\
\text { David, 2007) }\end{array}$ & $\begin{array}{l}\text { (Mahadevan \& } \\
\text { Mugler, 2008) }\end{array}$ \\
\hline Used techniques & dwt & ANFIS, FLNN & $\begin{array}{l}\text { cca-swt, sobi- } \\
\text { swt }\end{array}$ & WT & ica & $\begin{array}{l}\text { Hermite basis } \\
\text { function }\end{array}$ \\
\hline Artifact removed & emg \& eog & EOG \& EMG & EOG \& EMG & ECG & bcf & bcg \\
\hline Year & 2014 & 2015 & 2015 & 2007 & 2007 & 2008 \\
\hline $\mathrm{PSNR}(\mathrm{dB})$ & Medium & $\begin{array}{l}23.18 \text { (EOG), } \\
21.34 \text { (EMG) }\end{array}$ & $\begin{array}{l}-19(\mathrm{EOG}),-7.5 \\
(\mathrm{EMG})\end{array}$ & 5.64 & 2 & 0.9 \\
\hline $\operatorname{RMSE}(\mu \mathrm{V})$ & Low & $\begin{array}{l}0.6335 \text { (EOG), } \\
0.7853 \text { (EMG) }\end{array}$ & Low & Low & Medium & 0.1531 \\
\hline Feasible & Yes & $\begin{array}{l}\text { Only with EOG, } \\
\text { EMG }\end{array}$ & $\begin{array}{l}\text { For EOG and } \\
\text { EMG }\end{array}$ & Yes & No & Fair \\
\hline $\begin{array}{l}\text { Efficiency/ } \\
\text { Reliability }\end{array}$ & Acceptable & $\begin{array}{l}\text { High Extraction } \\
\text { Efficiency }\end{array}$ & $\begin{array}{l}\text { Efficient than } \\
\text { BSS-SCD }\end{array}$ & $97.5 \%$ & Not Optimal & Efficient \\
\hline Complexity & Least & Less & Less & Least & Complex & Less \\
\hline Speed & High & High & High & Very High & Low & High \\
\hline Data Duration & $10 \mathrm{~s}$ & $6 s$ & $4 \mathrm{~s}$ & 4-5 min & $180 \mathrm{~s}$ & $3500 \mathrm{~ms}$ \\
\hline $\begin{array}{l}\text { Sampling rate } \\
(\mathrm{Hz})\end{array}$ & 256 & 50 & 256 & 200 & 1024 & 1000 \\
\hline Sample data & - & 6000 & - & - & 8000 & - \\
\hline Channel number & $\begin{array}{l}10-20 \\
\text { system }\end{array}$ & $10-20$ system & 55 & $\begin{array}{l}10-20 \\
\text { system }\end{array}$ & 20 & 32 \\
\hline $\begin{array}{l}\text { Average } \\
\text { correlation } \\
\text { coefficient }\end{array}$ & 0.7574 & $\begin{array}{l}0.701 \text { (EOG), } \\
0.0633(\mathrm{EMG})\end{array}$ & $\begin{array}{l}.999 \text { (EOG), } \\
1.00 \text { (Emg) }\end{array}$ & 0.6138 & 0.8 & Satisfactory \\
\hline
\end{tabular}

ANFIS: Adaptive Neuro-Fuzzy Inference System, FLNN - Functional Link Neural Network 


\section{APPENDIX H}

Table 11. Feature comparison table for EMG artifact removal

\begin{tabular}{|c|c|c|c|c|c|c|}
\hline \multicolumn{7}{|c|}{ Authors Name and feature comparison of their paper } \\
\hline $\begin{array}{l}\text { Sequence } \\
\text { Number }\end{array}$ & 1 & 2 & 3 & 4 & 5 & 6 \\
\hline $\begin{array}{l}\text { Authors } \\
1 \\
\text { Features }\end{array}$ & $\begin{array}{l}\text { (Mijovic \& } \\
\text { Huffel, 2010) }\end{array}$ & $\begin{array}{l}\text { (Sweeney \& } \\
\text { Onaral, 2012) }\end{array}$ & $\begin{array}{l}\text { (Safieddine\& } \\
\text { Merlet, 2012) }\end{array}$ & $\begin{array}{l}\text { (Korhonen \& } \\
\text { Sarvas, 2011) }\end{array}$ & $\begin{array}{l}\text { (Chen \& Peng, } \\
\text { 2014) }\end{array}$ & $\begin{array}{l}\text { (Teng \& } \\
\text { Wang, 2014) }\end{array}$ \\
\hline $\begin{array}{l}\text { Used } \\
\text { techniques }\end{array}$ & eemd-ica & Eemd-ica & $\begin{array}{l}\text { ICA, CCA, } \\
\text { EMD, WT }\end{array}$ & ica & $\begin{array}{l}\text { eemD-Multi- } \\
\text { set cca }\end{array}$ & memd \\
\hline $\begin{array}{l}\text { Artifact } \\
\text { removed }\end{array}$ & $\begin{array}{l}\text { Muscle } \\
\text { Artifacts }\end{array}$ & $\begin{array}{l}\text { Motion } \\
\text { Artifacts }\end{array}$ & EMG & $\begin{array}{l}\text { Muscle } \\
\text { Artifacts }\end{array}$ & emg & emg \\
\hline Year & 2010 & 2012 & 2012 & 2013 & 2014 & 2014 \\
\hline $\operatorname{PSNR}(\mathrm{dB})$ & Good & 14.82 & - & Satisfactory & 4.4 & Good \\
\hline $\operatorname{RMSE}(\mu \mathrm{V})$ & 0.6479 & Low & $\begin{array}{l}\text { min with } 2 \mathrm{~T} \\
\text { EMD }\end{array}$ & Min & 0.19 & 0.9572 \\
\hline Feasible & Yes & Yes & $\begin{array}{l}\text { ICA for high } \\
\text { SNR and 2T- } \\
\text { EMD for low } \\
\text { SNR }\end{array}$ & Yes & Yes & Yes \\
\hline $\begin{array}{l}\text { Efficiency/ } \\
\text { Reliability }\end{array}$ & $\begin{array}{l}\text { Highly } \\
\text { Efficient }\end{array}$ & $\begin{array}{l}\text { For Motion } \\
\text { Artifact only }\end{array}$ & $\begin{array}{l}\text { Good at } \\
-30 \mathrm{~dB}, \\
\text { average at } \\
-25 \mathrm{~dB} \text {, less } \\
\text { efficient at } \\
20 \mathrm{~dB} \text { to }-5 \mathrm{~dB}\end{array}$ & Good & Effective & Efficient \\
\hline Complexity & $\begin{array}{l}\text { Highly } \\
\text { Complex }\end{array}$ & $\begin{array}{l}\text { Highly } \\
\text { Complex }\end{array}$ & $\begin{array}{l}\text { ICA High } \\
\text { complex }\end{array}$ & Complex & Medium & Less \\
\hline Speed & Least & Medium & $\begin{array}{l}\text { DWT High } \\
\text { speed }\end{array}$ & High & Medium & High \\
\hline Data Duration & $10 \mathrm{~s}$ & $9 \min$ & $8 \mathrm{~s}$ & - & $10 \mathrm{~s}$ & $8 \mathrm{~s}$ \\
\hline $\begin{array}{l}\text { Sampling rate } \\
(\mathrm{Hz})\end{array}$ & 250 & 200 & 256 & 1450 & 1000 & 200 \\
\hline Sample data & - & 500 & 2048 & - & 10000 & 1600 \\
\hline $\begin{array}{l}\text { Channel } \\
\text { number }\end{array}$ & 21 & 2 & 32 & 60 & 1 & 6 \\
\hline $\begin{array}{l}\text { Average } \\
\text { correlation } \\
\text { coefficient }\end{array}$ & Satisfactory & 0.765 & - & Satisfactory & 0.99 & Good \\
\hline
\end{tabular}




\section{APPENDIX I}

Table 12. Feature comparison table for EMG artifact removal continued

\begin{tabular}{|c|c|c|c|c|}
\hline \multicolumn{5}{|c|}{ Authors Name and feature comparison of their paper } \\
\hline Sequence Number & 7 & 8 & 9 & 10 \\
\hline $\begin{array}{l}\text { Authors } \\
\backslash \\
\text { Features }\end{array}$ & $\begin{array}{l}\text { (Anastasiadou \& } \\
\text { Mitsis, 2014) }\end{array}$ & (Chen \& Ward, 2014) & $\begin{array}{l}\text { (Anastasiadou \& } \\
\text { Mitsis, 2015) }\end{array}$ & $\begin{array}{l}\text { (Sardouie \& Merlet, } \\
\text { 2015) }\end{array}$ \\
\hline Used techniques & cca & eemd-Joint-bss & Cca-wt & jdica \\
\hline Artifact removed & Muscle Artifacts & emg & EMG & emg \\
\hline Year & 2014 & 2014 & 2015 & 2015 \\
\hline $\mathrm{PSNR}(\mathrm{dB})$ & Good & 3 & $\begin{array}{l}-5 \text { for }\left(1^{*}\right),-10 \text { for } \\
\left(14^{*}\right),-15 \text { for }\left(15^{*}\right),- \\
20 \text { in }\left(18^{*}\right)\end{array}$ & High \\
\hline $\operatorname{RMSE}(\mu \mathrm{V})$ & $\begin{array}{l}\left(.8349^{\wedge} / .1374^{*}\right) \\
\mathrm{a},\left(.2423^{\wedge} / .1807^{*}\right)^{\mathrm{b}}, \\
\left(.1023^{\wedge} / .0546^{*}\right)^{\mathrm{c}}\end{array}$ & 0.2 & $\begin{array}{l}0.8665\left(1^{*}\right), \\
0.8981\left(14^{*}\right), \\
0.9790\left(15^{*}\right), \\
0.8755\left(18^{*}\right)\end{array}$ & $\begin{array}{l}\text { Minimum with } \\
\text { JDICA }\end{array}$ \\
\hline Feasible & Fair & 0.98 & Yes & $\begin{array}{l}\text { Good with less no of } \\
\text { electrodes }\end{array}$ \\
\hline $\begin{array}{l}\text { Efficiency/ } \\
\text { Reliability }\end{array}$ & Satisfactory & Efficient & Efficient & $\begin{array}{l}\text { Best to Paediatric } \\
\text { Patient }\end{array}$ \\
\hline Complexity & Less & Medium & Medium & Complex \\
\hline Speed & High & Medium & Low & High \\
\hline Data Duration & $30 \mathrm{~m}$ & $10 \mathrm{~s}$ & $5 \mathrm{~min}$ & $20 \mathrm{~s}$ \\
\hline Sampling rate $(\mathrm{Hz})$ & 200 & 250 & 200 & 256 \\
\hline Sample data & - & - & 3000 & 5120 \\
\hline Channel number & $10-20$ system & 21 & $10-20$ system & 12 \\
\hline $\begin{array}{l}\text { Average correlation } \\
\text { coefficient }\end{array}$ & $.869^{\mathrm{a}} / .562^{\mathrm{b}} / .486^{\mathrm{c}}$ & Good & 0.9508 & Satisfactory \\
\hline
\end{tabular}

JDICA- Jacobi-like Deflationary ICA, First Subject- a, Second Subject- b, Third subject-c, Channel fp1- ${ }^{*}$, channel fp2- ^ . 


\section{APPENDIX $J$}

Table 13. Feature comparison table for automatic artifact detection and removal

\begin{tabular}{|c|c|c|c|c|c|c|}
\hline \multicolumn{7}{|c|}{ Authors Name and feature comparison of their paper } \\
\hline $\begin{array}{l}\text { Sequence } \\
\text { Number }\end{array}$ & 1 & 2 & 3 & 4 & 5 & 6 \\
\hline $\begin{array}{l}\text { Authors } \\
1 \\
\text { Features }\end{array}$ & $\begin{array}{l}\text { (Mammone\& } \\
\text { Morabito, } \\
\text { 2012) }\end{array}$ & $\begin{array}{l}\text { (Akhtar \& } \\
\text { James, 2012) }\end{array}$ & $\begin{array}{l}\text { (Sweeney \& } \\
\text { Ward, 2013) }\end{array}$ & $\begin{array}{l}\text { (Mert \& } \\
\text { Akan, 2013) }\end{array}$ & $\begin{array}{l}\text { (Islam \& } \\
\text { Yang, 2014) }\end{array}$ & $\begin{array}{l}\text { (Chuang \& } \\
\text { Lin, 2014) }\end{array}$ \\
\hline $\begin{array}{l}\text { Used } \\
\text { techniques }\end{array}$ & AWICA & scica-wT & eemd-cca & emd & SWT & ICA-EMD \\
\hline $\begin{array}{l}\text { Artifact } \\
\text { removed }\end{array}$ & $\begin{array}{l}\text { Automatic } \\
\text { Artifact } \\
\text { Detection and } \\
\text { Removal }\end{array}$ & $\begin{array}{l}\text { Automatic } \\
\text { Artifact } \\
\text { Detection and } \\
\text { Removal }\end{array}$ & $\begin{array}{l}\text { Automatic } \\
\text { Artifact } \\
\text { Detection and } \\
\text { Removal }\end{array}$ & $\begin{array}{l}\text { Automatic } \\
\text { Artifact } \\
\text { Detection and } \\
\text { Removal }\end{array}$ & $\begin{array}{l}\text { Automatic } \\
\text { Artifact } \\
\text { Detection and } \\
\text { Removal }\end{array}$ & $\begin{array}{l}\text { Automatic } \\
\text { Artifact } \\
\text { Detection and } \\
\text { Removal }\end{array}$ \\
\hline Year & 2012 & 2012 & 2013 & 2013 & 2014 & 2014 \\
\hline $\operatorname{PSNR}(\mathrm{dB})$ & Satisfactory & Satisfactory & 8.21 & 27.34 & $\begin{array}{l}\text { Max } 17.6 \text { (at } \\
25 \mathrm{~dB} \text { ) }\end{array}$ & Satisfactory \\
\hline $\operatorname{RMSE}(\mu \mathrm{V})$ & $\begin{array}{l}\left(.13^{\mathrm{c}} / .12^{\mathrm{d}}\right)^{1}, \\
\left(.12^{\mathrm{c}} / .15^{\mathrm{d}}\right)^{2}, \\
\left(.05^{\mathrm{c}} / .05^{\mathrm{d}}\right)^{3}, \\
\left(.09^{\mathrm{a}} / .1^{\mathrm{b}}\right)^{4}\end{array}$ & $\begin{array}{l}-35.264^{\mathrm{a}}, \\
-31.331^{\mathrm{b}}\end{array}$ & Low & Medium & $\begin{array}{l}\text { Min .02 (at } \\
5 \mathrm{~dB})\end{array}$ & 0.19 \\
\hline Feasible & Fair & No & Yes & No & Yes & Yes \\
\hline $\begin{array}{l}\text { Efficiency/ } \\
\text { Reliability }\end{array}$ & $\begin{array}{l}\text { Effective } \\
\text { Artifact } \\
\text { Suppression }\end{array}$ & Inconsistent & $\begin{array}{l}\text { Fairly efficient } \\
\text { than ICA and } \\
\text { WT }\end{array}$ & High Efficient & $80 \%$ & $84 \%$ \\
\hline Complexity & Moderate & Complex & Moderate & Less & Least & High Complex \\
\hline Speed & Low & Low & Medium & High & Least & Low \\
\hline Data Duration & $5 \mathrm{~s}$ & $20 \mathrm{~s}$ & $20 \mathrm{~s}$ & $5 \mathrm{~s}$ & $100 \mathrm{~s}$ & $1 \mathrm{~s}$ \\
\hline $\begin{array}{l}\text { Sampling rate } \\
(\mathrm{Hz})\end{array}$ & 128 & 200 & 200 & 200 & 200 & 500 \\
\hline Sample data & 512 & 4000 & - & 100 & - & - \\
\hline $\begin{array}{l}\text { Channel } \\
\text { number }\end{array}$ & 8 & 6 & 2 & 1 & 16 & $10-20$ system \\
\hline $\begin{array}{l}\text { Average } \\
\text { correlation } \\
\text { coefficient }\end{array}$ & 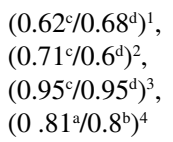 & - & High & Satisfactory & - & 0.95075 \\
\hline
\end{tabular}

a- $\mathrm{CH} 1, \mathrm{~b}-\mathrm{CH} 2, \mathrm{c}-\mathrm{CH} 3, \mathrm{~d}-\mathrm{CH} 4$, 1-electrical trend, 2- linear shift, 3- muscle, 4- eye blink, Number of channels- ${ }^{*}$, 


\section{APPENDIX K}

Table 14. Feature comparison table for automatic artifact detection and removal continued

\begin{tabular}{|c|c|c|c|c|}
\hline \multicolumn{5}{|c|}{ Authors Name and feature comparison of their paper } \\
\hline Sequence Number & 7 & 8 & 9 & 10 \\
\hline $\begin{array}{l}\text { Authors } \\
1 \\
\text { Features }\end{array}$ & $\begin{array}{l}\text { (Priyadharsini \& } \\
\text { Rajan, 2014) }\end{array}$ & (Daly \& Putz, 2015) & $\begin{array}{l}\text { (Radüntz \& Meffert, } \\
\text { 2015) }\end{array}$ & (Islam \& Yang, 2015) \\
\hline Used techniques & ANFIS-PSO* & ICA-WT & ICA-LDA & Wt \\
\hline Artifact removed & $\begin{array}{l}\text { Automatic Artifact } \\
\text { Detection and } \\
\text { Removal }\end{array}$ & $\begin{array}{l}\text { Automatic Artifact } \\
\text { Detection and } \\
\text { Removal }\end{array}$ & $\begin{array}{l}\text { Automatic Artifact } \\
\text { Detection and } \\
\text { Removal }\end{array}$ & $\begin{array}{l}\text { Automatic Artifact } \\
\text { Detection and } \\
\text { Removal }\end{array}$ \\
\hline Year & 2014 & 2015 & 2015 & 2015 \\
\hline $\mathrm{PSNR}(\mathrm{dB})$ & $\begin{array}{l}(0.0781 / 15.0245)^{\mathrm{a}} \\
(1.0294 / 21.8553)^{\mathrm{b}}\end{array}$ & Satisfactory & Satisfactory & High \\
\hline $\operatorname{RMSE}(\mu \mathrm{V})$ & $\begin{array}{l}(5.1424 \mathrm{e}-004)^{\mathrm{a}}, \\
(5.8904 \mathrm{e}-004)^{\mathrm{b}}\end{array}$ & $\begin{array}{l}0.0107 \pm 0.017^{1} \\
0.1035 \pm 0.0629^{2} \\
0.0081 \pm 0.007^{3} \\
0.0001 \pm .00003^{4} \\
0.0036 \pm 0.0073^{5}\end{array}$ & Low & 0.64 \\
\hline Feasible & Yes & Yes & Fair & Yes \\
\hline $\begin{array}{l}\text { Efficiency/ } \\
\text { Reliability }\end{array}$ & Efficient than ANFIS & Efficient & $87.7 \%$ & Efficiency Improved \\
\hline Complexity & Less & Complex & Complex & Least \\
\hline Speed & High & Low & Low & Very High \\
\hline Data Duration & $4 \mathrm{~s}$ & $4 \mathrm{~s}$ & $94.34 \mathrm{~s}$ & $5 \min$ \\
\hline Sampling rate $(\mathrm{Hz})$ & 256 & 512 & 500 & 256 \\
\hline Sample data & 1000 & - & - & - \\
\hline Channel number & $10-20$ system & & 25 & 32 \\
\hline $\begin{array}{l}\text { Average correlation } \\
\text { coefficient }\end{array}$ & Good & & Satisfactory & 0.9891 \\
\hline
\end{tabular}

a-CH1, b-CH2, 1-Blink artifact, 2- Movement artifact, 3- Moving artifact, 4- Failing electrode, 5-Slow EOG electrode

*ANFSI PSO-Adaptive Neuro-Fuzzy Inference System-Particle Swarm Optimization, LDA- Linear Discriminant Analysis 
Vandana Roy is working as an associate professor in Electronics Communication Department in Hitkarini College of Engineering and Technology, Jabalpur. She has 05 years of Industrial experience and 14 years of teaching and research experience. She has awarded her doctorate degree in biomedical signal processing in 2018 from RGPV, Bhopal. She has received B.E. degree in Electronics and communication engineering from RGPV, Jabalpur in 2001 and the M. Tech. degree in Digital Communication from Rajiv Gandhi Technical University, Bhopal in 2010. Her research interests are Communication, Image processing, Bio-medical Signal Processing, Machine learning and Wireless Network. She has published more than 45 Research papers in International/National Journals and conferences. 04 research papers are published in SCIE journals. She is actively serving as a Reviewer in Various IEEE, Springer, IGI Global International Publishers Journals and also Editorial Board Member of many reputed Journals.

Prashant Kumar Shukla is working as an Assistant Professor (SG) and Research Coordinator in the Department of Computer Science \& Engineering, School of Engineering \& Technology, Jagran Lakecity University, Bhopal from July, 2019. He is PhD in Computer Science and Engineering from Dr K. N. Modi University, Rajasthan. He is Master of Engineering from Rajiv Gandhi Proudyogiki Vishwavidyalaya, Bhopal. He is in research, teaching and industry for the past 19 years and working in the research areas like Machine Learning, Deep Learning, Computer Vision, Internet of Things (IOT) etc. He has applied for 24 patents, in which 23 patents has been published. He has received funding for 2 research projects. He has published and presented more than 23 research papers in various national and international SCl/ web of science / Scopus/Indexed journals and conferences. He has published 02 Chapters in Scopus indexed edited book available in Google Books. He has received various awards as "Innovative Teacher Award" by GISR Foundation and The American College of DUBAI at Dubai, UAE, and "Best Researcher" by ESN Publications, Tamilnadu, India and "Teacher Innovation Award" by ZIIEI, Sri Aurobindo Society, India, and Green ThinkerZ Preeminent Researcher award 2019 by Green ThinkerZ Society, Chandigarh. He has been contributing to several professional institutions like IAENG, IACSIT and SDIWC. He is a member of Tuning India project which is Co-funded by the Erasmus+ Programme of the European Union. He is a member of around 25 editorial and reviewer board in national and international research journals. He has attended and organized more than 33 workshop, seminar, conference, FDP and training programs. He is associated with 2 startups also.

Amit Kumar Gupta received MCA degree from kurukshetra university Haryana. He received his PhD (CS) from Bundelkhand University Jhansi, 2014. He is currently as Associate Professor in the Department of Computer Applications at KIET Group of Institutions, Ghaziabad, Affiliated from AKTU, Lucknow. His research interest include Artificial Intelligence, Fuzzy logic, Neural Networks, Mobile computing, Wireless computing, computer network. He has published 40 plus research paper in international journal and conferences. He has one patent and one book on mobile computing.

Vikas Goel received B. Tech. degree (I'st Div.) in Information Technology from MIET college under VBS Purvanchal university in 2001 and M. Tech. degrees (I'st Div.) in computer science from Shobhit University in 2009. He received his Ph.D. (CSE) from Uttarakhand Technical University, Uttarakhand, 2017. He is currently an Associate Professor in the IT Department at KIET Group of Institutions affiliated from AKTU, Lucknow from January 2020 onwards. He has a vast experience of 18+ years of teaching in various good institutes. He has served COER Roorkee, AKGEC Ghaziabad and IMS Ghaziabad. He has published more than 30 papers in International journals and conferences. He has three SCI index papers, 12 Scopus index papers and more than 20 papers in International conferences of IEEE, Springer, ACM and Elsevier. His research interests include mobile computing, wireless computing, broadcasting data in mobile devices, distributed computing, sentiment analysis. He has guided two Ph.D. students as Co-guide. He has guided nine M.Tech. students for dissertation.

Piyush Kumar Shukla [(SMIEEE, LMISTE, PDF (Computer Engineering), PhD (CSE), M. Tech (CSE)), BE (EC)] is Associate Professor in CSE, UIT-RGPV (Technological University of Madhya Pradesh), Bhopal, M.P., India, since 2007. He has published more than 100 research papers/ book chapters/ at National/International level. Four edited books on Blockchain for Information Security \& Privacy (CRC Press/Taylor \& Francis), Innovative Engineering With AI Applications (Wiley-SP), Internet of Everything (IoE) for Biomedical Applications, Intelligent Sensor Nodebased Systems and Applications in Engineering and Sciences (CRC Press/Taylor \& Francis-AAP) are almost under completion; active reviewer/editorial member in various journals including IEEE Transactions/ Elsevier/ Springer etc., delivered various Talks/Chaired Technical Sessions. He is PI on "Precision Agriculture: Smart Farming with IOT and Drone for increasing productivity of Crops in India" project funded by TEQIP-III. He has Supervised 07 $P h D$ \& 50 PG dissertations till date; research interest includes ML, Security, Blockchain, IoT, and FANET.

Shailja Shukla received B.E. degree in Electrical Engineering from Jabalpur Engineering College, Jabalpur in 1984 and the Ph.D. degree in Control System from Rajiv Gandhi Technical University, Bhopal in 2002. She is currently Professor in Electrical Engineering and the Chairperson of the Department of Computer Science and Engineering at Jabalpur Engineering College, Jabalpur. Her research interest on Large Scale Control Systems, Soft Computing and include Machine Learning, Face Recognition, image processing and Digital Signal Processing. She has been the Organizing Secretary of International Conference on Soft Computing and Intelligent Systems. She has published more than 70 Research papers in International/National Journals and conferences. She is Editorial member of many International Journals. 